\title{
OPPORTUNITIES TO UTILIZE THE POTENTIAL OF AUGMENTED REALITY TO INTERACT WITH PHOTOGRAPHIC MATERIAL IN MUSEUM AND ARCHIVE COLLECTIONS
}

\author{
by \\ Hilkka Ingrid Forster
}

BFA, Concordia University, Montreal, Quebec, 2010

MA, Ryerson University, Toronto, Ontario, 2015

\author{
A thesis \\ presented to Ryerson University \\ in partial fulfillment of the requirements for the degree of \\ Master of Digital Media \\ In the program of \\ Digital Media
}

Toronto, Ontario, Canada, 2018

(C) Hilkka Ingrid Forster, 2018 


\section{Author's Declaration}

I hereby declare that I am the sole author of this MRP. This is a true copy of the MRP, including any required final revisions.

I authorize Ryerson University to lend this MRP to other institutions or individuals for the purpose of scholarly research.

I further authorize Ryerson University to reproduce this MRP by photocopying or by other means, in total or in part, at the request of other institutions or individuals for the purpose of scholarly research.

I understand that my MRP may be made electronically available to the public.

Hilkka Ingrid Forster 


\begin{abstract}
OPPORTUNITIES TO UTILIZE THE POTENTIAL OF AUGMENTED REALITY TO INTERACT WITH PHOTOGRAPHIC MATERIAL IN MUSEUM AND ARCHIVE COLLECTIONS

\author{
Hilkka Ingrid Forster \\ Master of Digital Media, Digital Media \\ Ryerson University, 2018
}

The use of Augmented Reality (AR) as an immersive and interactive engagement tool for art and cultural institutions is increasing. AR, when used in a meaningful way, has shown great potential for discovery-based learning experiences. My research considers the potential of AR for photographic collections in museums and archives by addressing two key questions. How can digital tools like AR serve to enhance our understanding of photographs as both object and image? What are the implications and limitations of this technology when used for this purpose? These questions are explored further in the form of a creative project that builds on how AR can be used to enhance interaction with photographic material in archives. These questions are explored further in the form of a creative project that builds on how AR combined with multimedia storytelling can be used to interact with photographic material in archives. 


\section{Acknowledgements}

I would like to begin by thanking all those who helped me to realize this project both conceptually and technically. Firstly, I would like to thank my thesis supervisor Dr. Richard Lachman for his guidance, expertise and enthusiasm, and for encouraging me to go beyond just writing a paper and create something I was passionate about. I would also like to thank Kathryn McKenzie for supervising my directed study. Thank you to our course instructor Matt Marshall for providing me with the technical foundation needed to pursue an augmented reality project and for his time and patience. Thank you to Am Sagarwala for ensuring that I had the equipment needed to complete this project and for acquiring new iPads for the MDM program. A big thank you to everyone at the Nova Scotia Archives for assisting me with my research and helping me navigate the archive, and for answering what must have seemed like an endless list of questions. Thank you also to the NSA for providing me with access to the Clara Dennis Fonds and for giving me permission to use the material for my MRP. I would also like to acknowledge all of the museum professionals - too many to name here — that I interviewed, chatted with and consulted for my research. Thank you for sharing your thoughts and insights on digital media and museum interaction. Peter Greenall, thank you for continually reminding me why I decided to go back to school and do a second masters degree and for your unwavering encouragement and support. Lastly, I would like to thank my dog Neville for his steadfastness and for providing comical relief and emotional support during stressful moments. 


\section{Table of Contents}

$\begin{array}{ll}\text { Author's declaration } & \text { ii }\end{array}$

Abstract

Acknowledgements

List of Illustrations $\quad$ vi

Introduction 1

$\begin{array}{ll}\text { Research Motivation } & 2\end{array}$

Part I: Informing Framework and Related Concepts 3

Part II: Creative Project: A Prototype for an Interactive Multimedia Application that Combines Augmented Reality and Storytelling with Photographs and Related Material from an Archival Collection

Part A: The Clara Dennis Fonds and Related Research 20

Part B: Research and Design Process

Concluding Thoughts and Future Opportunities 44

$\begin{array}{ll}\text { References } & 46\end{array}$

$\begin{array}{ll}\text { Endnotes } & 49\end{array}$ 


\section{List of Illustrations}

Figure 1. Visitor at the Art Gallery of Ontario (AGO) using the ReBlink App. The image shows the remixed version of the painting Village Scene in Winter (1850), by Cornelius Krieghoff, in augmented reality. Courtesy of ReBlink artist Alex Mayhew and Impossible Things.

Figure 2. Screenshot of phone interface while in the augmented reality experience using the Skin \& Bones App at the Smithsonian National Museum of Natural History. This image depicts the overlay that appears when the user holds their phone up to an animal skeleton in the Hall of Bones. Courtesy of author.

Figure 3. Three images showing the research process at the Nova Scotia Archives. Archival material seen is from the Clara Dennis Fonds.

Figure 4. Samples of the visual mind maps created during the organization stage of the project.

Figure 5. Left: Photograph of the current road leading up to the Cap-Rouge hiking trail on Cape Breton Island, taken by the author. Centre: Photograph of the old road ascending Cap-Rouge on Cape Breton Island, taken by Clara Dennis, Courtesy of the Nova Scotia Archives. Right: Photograph of the head of the Cap-Rouge hiking trail in the Cape Breton Highlands National Park, taken by the author. 31

Figure 6. Left: Launch screen of the prototype design created in Adobe XD. Centre: Home screen of the prototype design created in Adobe XD. Right: Pop-up message in

the prototype design created in Adobe XD prompting user to use headphones and turn up the device volume.

Figure 7. Screen from the prototype design created in Adobe XD showing the instruction screen and related pop-up. The screen tells the user how to activate the AR experiences by finding an image target.

Figure 8. Left: Hidden pop-up menu in the prototype design created in Adobe XD. Right: When the info button is selected from the hidden pop-up menu an icon legend appears.

Figure 9. Interface of the app prototype created in Adobe XD: what the user sees during an AR activation holding the iPad in front of an image target. Also shown is the information/exhibition label activation.

Figure 10. Interface of the app prototype created in Adobe XD: representation of what the user sees during an AR activation holding the iPad over photographs in books published by Clara Dennis. Top: AR event showing a 3D model of the Bluenose 
Schooner, activated by a photograph of the Bluenose Schooner from the book Down in Nova Scotia. Bottom: AR event showing a video overlay, activated by a photograph of the Atlantic Ocean after a storm from the book Down in Nova Scotia.

Figure 11. Interface of the app prototype created in Adobe XD: representation of what the user sees during an AR activation holding the iPad over one of Clara Dennis's notebooks. Shown here is the AR magnifying glass event.

Figure 12. Interface of the app prototype created in Adobe XD: representation of what the user sees during an AR activation holding the iPad over one of Clara Dennis's pieces of correspondence. The AR event shown here is an overlay of a writing animation and additional letters that the user can scroll through.

Figure 13. Photograph of an individual engaging with the onsite exhibition and testing the AR prototype at the MDM Showcase. Photograph taken by the author.

Figure 14. Screenshot of what the user sees during an AR activation. Left: 3D model of Clara Dennis's car appears on top of a map of Nova Scotia in the front cover of one of her books. Right: 3D model of the Bluenose Schooner appears on top of a photograph of the Bluenose in Clara Dennis's book More About Nova Scotia. 43

Figure 15. Left: A printed reproduction of one of Clara Dennis's photographs found in the Clara Dennis Fonds at the Nova Scotia Archives. Right: Screenshot of what the user sees during an AR activation: a video overlay of the Atlantic Ocean captured at the same location where the photograph was originally taken. 


\section{Introduction}

Sometimes you need to touch something to better understand it, but fulfilling that desire is not always possible. Take photographic objects—interacting with their physicality is seldom possible for researchers and members of the public alike. Photographs are understood as both object and image, a duality that generates debate in terms of how photographs are used for research, how they are exhibited and managed (physically and digitally), and how they are preserved in archives and museum collections. Given this dual status, it is worth considering the use of current digital technology as a means of interacting with photographic collections. For instance, the use of Augmented Reality (AR) as an immersive and interactive engagement tool for art and cultural institutions is increasing. AR, when used in a meaningful way, has shown great potential for discovery-based learning experiences. Augmented reality is a technology that superimposes a digital layer on a user's view of the real world through a device like a smartphone or tablet using the device's camera vision. Unlike virtual reality (VR) where the user is totally immersed within a computer-generated simulation of a three-dimensional environment, AR allows the user to remain in the real world, without the need for content viewing hardware or head-mounted displays. Mixed reality (MR), on the other hand, merges the virtual world with the real world, creating an environment in which digital and physical objects co-exist and interact with each other.

In Part I of this paper, I will consider AR's application for photographic collections in museums and archives. How can digital tools like AR serve to enhance our understanding of photographs as both object and image? What are the implications and limitations of this technology when used for this purpose? In Part II of this paper, I will discuss how these research questions have been explored further through a creative project. The creative project takes the 
form of a prototype for an interactive AR experience, where AR and storytelling are combined to enhance our understanding of photographs as both object and image, using photographs and related material from the Clara Dennis fonds at the Nova Scotia Archives.

\section{Research Motivation}

As someone who has worked with archives and collections of photographic material, I recognize there is a growing demand for the use of digital media to not only enhance engagement with this material but provide access to it in new and innovative ways. There are still limitations to utilizing technology like augmented reality to its full potential within art and cultural institutions - discussed in this paper-as well as hesitations due to restrictions in cultural policy. I aim to demonstrate that this technology can be used in a meaningful and non-gimmicky way. My goal is to become a specialist in this area and look for opportunities to work as a digital media strategist and concept designer for art and culture projects in the future, either as an external partner or employee. My goal for this project, specifically, is to create a prototype for a meaningful AR experience to test this approach and determine its value for photographic collections and archives, in addition to building new skills in digital media technologies, interactive multimedia storytelling, and augmented reality. I feel that acquiring a technical understanding of augmented reality and the related software tools and developer platforms is essential in order to effectively provide creative direction and strategy to a project team; this is why I chose to go beyond the prototype design stage and build a basic AR project. 


\section{Part I: Informing Framework and Related Concepts}

Museum and archives professionals can agree that, sadly, a large percentage of material in collections never gets seen by the public, utilized for exhibitions, or even accessed for research. These fascinating objects remain housed in boxes and rarely leave their home on a shelf in the vault. The transition that museums and art institutions have undergone since the emergence of digital technology, trying to provide access to this material, can be understood in three phases. Initially, the goal was to have as much of a collection digitized as possible, so it could be properly catalogued and then put online to be accessed by researchers and the public - $\mathrm{a}$ process that continues to depend heavily on funding. The second phase involved doing something with these now digitized works in the form of online exhibitions, as well as disseminating the works across social media platforms for marketing, sharing, and engagement. The third phase is a more innovative one. The question has now shifted to: how can we use this digitized material combined with current digital technology to engage new and evolving audiences in meaningful ways? Museums can experience all three phases simultaneouslypriority might be given to one collection over another or specific objects from a collection might be digitized and online while others are not. A subset of a collection might be used for an exhibition and thus made available for a digital project, for example. Funding and resources might be allocated for a subject-specific project that is of current socio-cultural or historical relevance, allowing the museum to incorporate more expensive digital technology.

It is important to acknowledge, however, that many museums and archives are still in phase one — getting collections digitized — due to lack of resources and funding. In an effort to address this issue of access, institutions have gone to great lengths to share their collections online. Museums and archives that do have the means to go beyond just digitization of their 
collection seem to direct their resources to online catalogues, virtual exhibitions, digitally curated projects, and social media. More immersive digital experiences like 360 tours and interactive self-guided tour apps are a popular choice for art and cultural institutions, while virtual reality and augmented reality continue to find their place within the museum experience. Visitors can watch a painting come to life by holding a smart phone in front of it, see 3D dinosaurs roam around a museum, interact with animal skeletons, and make discoveries at historic sites in AR outside the museum walls. ${ }^{i}$ Augmented reality has quickly become a tool to enhance interaction with museum objects and collections material, and shape how we understand them, by delivering additional information and rich media to the user. Although AR has existed within mainstream consumer technology for several years, it is only recently that the use of this technology has gained credibility within museum practice as a potential engagement and educational tool. Mandy Ding, in her article "Augmented Reality in Museums" in The Augmented Museum: Essays on Opportunities and Uses of Augmented Reality in Museums (2018), notes this potential:

"Already on a path of convergence with mobile technology, AR has become a portable tool for discovery-based learning that can enhance the information available to patrons when visiting gallery spaces, interacting with real-world objects, or even exploring outdoor installations" (Ding, 14).

Similarly, AR shows great potential as an interactive tool for viewing objects in photographic collections. What if you could hold a smart phone or tablet over a 19th century salted-paper print and simultaneously see the negative it was made from, while also learning more about the positive-negative process? Daguerreotypes are pretty magical photographic objects that you often only see displayed in a case, but rarely get to touch or interact with. ${ }^{\text {ii }}$ What if a desired interaction could be simulated in AR? Or what if you could learn about how 
Daguerreotypes were made, be transported into a Daguerreotypist's studio through the interface of a smart device, while still viewing the physical object?

Just as AR has been used in the cultural heritage sector for discovery-based learning and to enhance self-guided experiences both in and outside the museum, it could equally be applied to photographic materials leading to the question: what unique possibilities and interactions does AR provide that other digital technologies or platforms do not?

\section{Digital Disruption in the Museum Space}

In the spring 2018, a collective of eight Internet/digital artists called MoMAR, disrupted the traditional museum-going experience at the Museum of Modern Art (MoMA) in New York City with their Augmented Reality project called "Hello, we're from the internet." 'iii The collective conceived a group installation in AR, in which their own digital artworks appeared as an overlay on top of paintings by American Abstract Expressionist artist Jackson Pollock (19121956) (DeGeurin 2018). By downloading the app onto a smart phone or tablet, anyone could experience the artworks while standing in the Jackson Pollock room. The app used image targets (the Pollock paintings) to trigger the AR experiences. The collective of artists did not have permission from the MoMA to execute the project, but that was very much the point. In the same manner the artists disrupted the exhibition space with AR, they disrupted the institution's name-MoMAR being an obvious, but clever, play on MoMA. To the same effect, MoMAR's website (momar.gallery) appears as an overlay on top of the MoMA's website. According to members of the collective, the project was a statement on elitism within the artworld, questioning the ownership of culture; AR in this instance became a democratizing tool that allowed artists to claim space that otherwise would not be accessible to them (momar.gallery). One of the 
participating artists, Barcia-Colombo, was quoted saying, "It's funny, because even people who were just visiting MoMA seem to primarily experience the work through the lens on their phones by taking selfies or photos of the work. Our AR work added an extra layer of digitization by hacking the pre-existing work to reveal the work of artists who are experimenting with a new form" (DeGeurin 2018).

Although museum professionals might be inclined to gasp in horror, the real takeaway from this "illegal" art intervention should be that the digital artists were tapping into an already existing trend in how we, as a society, now consume art and culture - through the interface and lens of a smart phone. Any museum existing in the $21^{\text {st }}$ century should anticipate participatory action from their audiences and learn to harness these opportunities. Given this, is this form of virtual trespassing really that inappropriate, especially within the context of a modern art museum? As Nina Simon writes, "The cultural and technological shifts that accompanied the rise of the social Web have changed people's expectations of what makes experiences worthwhile or appealing. People assume the right to co-opt and redistribute institutional content, not just to look at it" (Simon 2010). While Simon was not specifically addressing multi-modal experiences such as AR, her acknowledgement of participatory culture speaks to a shift in how museum audiences expect to interact with museum content. 


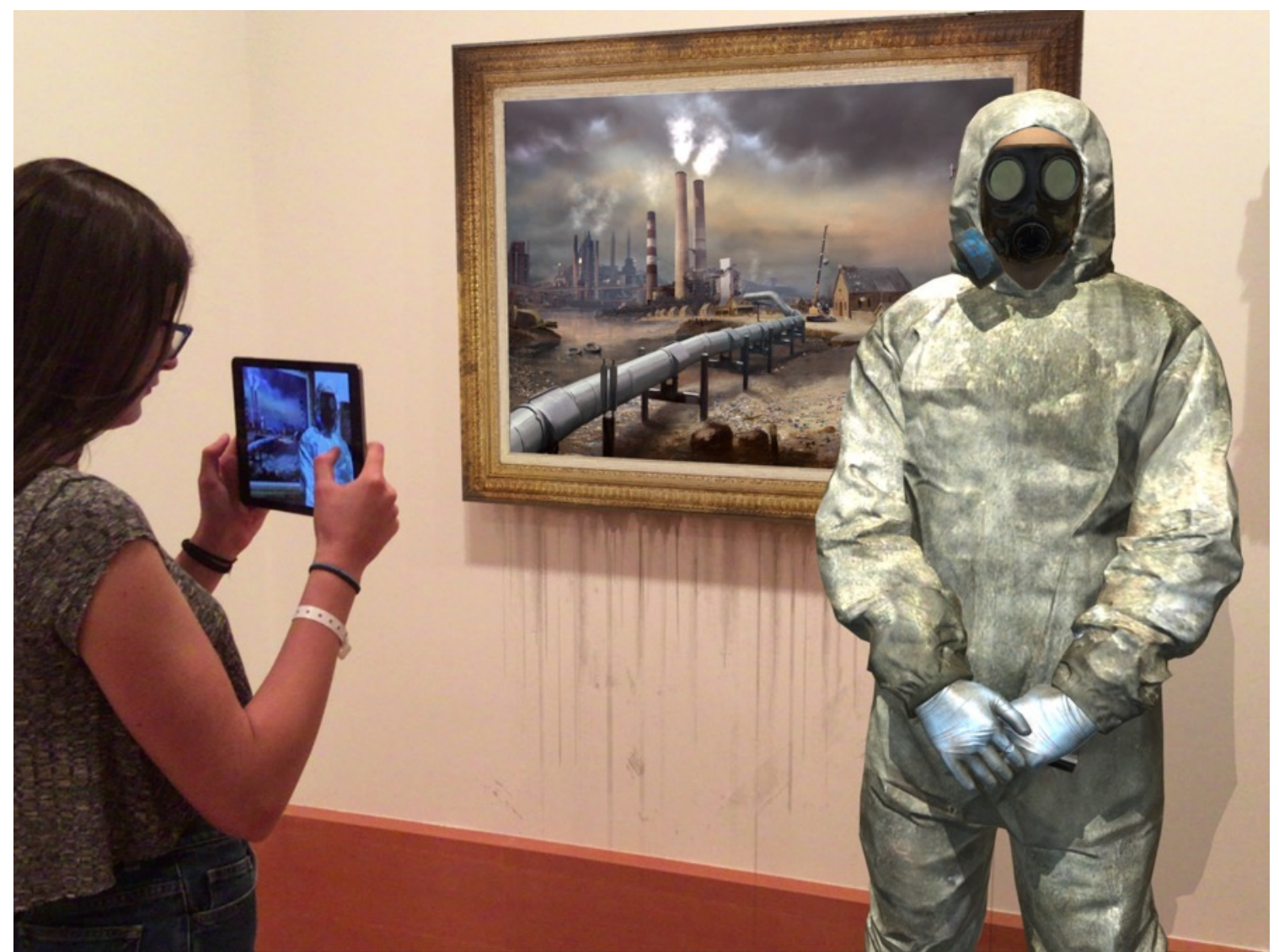

Figure 1. Visitor at the Art Gallery of Ontario (AGO) using the ReBlink App. The image shows the remixed version of the painting Village Scene in Winter (1850), by Cornelius Krieghoff, in augmented reality. Courtesy of ReBlink artist Alex Mayhew and Impossible Things.

In July of 2017, the Art Gallery of Ontario (AGO) in Toronto, Canada unveiled a unique AR project called ReBlink, designed and executed by Toronto-based digital artist Alex Mayhew and his company, Impossible Things. The exhibition ran at the AGO until April $8^{\text {th }}, 2018$. By juxtaposing two realities, ReBlink demonstrated how AR can be used intelligently to create a dialogue between the past and the present. Older works of art were re-interpreted and new narratives were formed. The exhibition encouraged visitors, using their smart phone device or one of the iPads installed in the space, to interact with selected paintings from the AGO's 
European and Canadian collections. Using an augmented reality app called ReBlink, users could hold their smart device up to a painting and watch it come to life; they saw a twenty-first century version of the original painting with changed elements. The paintings became three-dimensional and could be explored from various angles. There was also an opportunity for viewers to become part of the artwork and share their experience on social media. Floor signage told both the participant and the photographer where to stand, as subjects from two paintings virtually gathered together for a group portrait. The use of augmented reality in this context was not gimmicky but instead created new meaning by re-contextualizing older works of art with a virtual layer of commentary inspired by the original paintings. Thus, the app and intervention had the original works at the forefront, while extending the experience of the visitor in meaningful ways through AR.

Similarly, renowned Canadian photographer Edward Burtynsky (1955-) launched an AR experience as part of his Anthropocene Project at Photo London in May 2018. ${ }^{\text {iv }}$ The Anthropocene Project, to be exhibited later this year at the Art Gallery of Ontario and the National Gallery of Canada in September 2018, will include both virtual and augmented reality experiences. By downloading an app on a smart device, exhibition goers will be able to experience select large-scale, high-resolution murals in AR. ${ }^{\mathrm{v}}$ The depiction of a Carrara marble quarry comes to life using AR and "when visitors hold a device up to the print, the image on the screen pans out to reveal the magnitude of the scene, complete with moving trucks and diggers" (Shaw 2018). Burtynsky's decision to use augmented reality to bring his photography to life and make his work even more immersive aids in strengthening the argument for AR applications and photography. 
Each of the aforementioned examples - from the interventionist MoMAR to immersive experiences such as ReBlink and the Anthropocene which intentionally extend situated exhibitsdemonstrate how AR can be used effectively to engage viewers with works in a meaningful way. Although these projects present exciting opportunities for using AR, it is still important to recognize that there are limitations and implications of using this technology for interacting with collections material. I will discuss some of these challenges in the next section.

\section{Limitations and Implications of Using AR for Museums and Archives:}

\section{A challenge to authenticity?}

It is important to note that the authenticity of a digital replica or digital copy of a museum object (one that exists in a digital or virtual space) remains a concern within museum practice. In his article "Even Better than the Real Thing? Digital Copies and Digital Museums in a Digital Cultural Policy," Ole Hylland writes that "for more than twenty years, many varied ideas on the merging of museum collections with digital technology and networking computers have been circulating" (Hylland, 2). Hylland refers to previous observations on the use of digital technology in museums, quoting Susan Keene who, in 1996, wrote:

[Will] it really change their nature in fundamental ways? It is far from clear as yet who are the users, and what they might want. If a museum disregards the seductive new technology, or finds it too expensive, will the institution wither away? Or will it thrive regardless of whether the information superhighway is just a vast distraction from its real business? (Hylland, 2).

The concerns expressed by Keene still linger today, as museums try to redefine their purpose and direction in a digital age as keepers of authenticity. According to Hylland: "the development of digitized museums and collections highlights and challenges in a profound way 
the museums' notions of authenticity, as well as the dichotomy between original and copy" (Hylland).

A digital representation should not attempt to replace an original object, but as Hylland questions, what will replace claims for authenticity that are potentially threatened by digital representations and how will this affect cultural policy? A museum's existence is legitimized by government and public support and much of this support is earned through museums acting as guardians of authentic objects and their perceived value; this is an integral aspect of cultural policy and any challenge to what Hylland refers to as the authenticity tradition, also becomes a challenge to cultural policy (Hylland, 3).

The general concern over how the role of cultural heritage institutions is changing in the face of digital technology can be further identified throughout museum scholarship. Jennifer Trant in her essay "When All You've Got is 'The Real Thing': Museums and Authenticity in the Networked World" notes the challenge that museums face over authenticity and quality in a context where museums must respond to various interpretations of cultural value having been "forced into an awareness that they are no longer the sole interpreters of their collections" (Trant, 306-313). Trant, considering the new digital landscape, asks how the traditional roles of author, editor, publisher, distributor, and consumer have changed and how this will impact interpretive strategies in institutions. "When authors are creators and anyone can be a publisher, what is the place and role of cultural institutions? Where and how can they find their niche, as relevant players in the digital world" (Trant, 306). In this case, how can museums remain relevant within our current participatory culture, while also maintaining their role as valuable interpreters of culture and heritage? The MoMAR intervention is a prime example of this concern outlined by Trant. 
The idea of a "superior" physical counterpart to digital representations of museum objects can be understood as part of a larger discourse identified by Fiona Cameron, as the "objectcenteredness of museum culture" (Cameron et al., 49). Cameron notes that conventions that have informed the value, meaning, and presence of digital objects come from conventional heritage discourses and material culture paradigms. Cameron points out that the discourses surrounding this issue are inclined to focus on the status of the digital copy as being inferior and lacking authenticity compared to its original; the digital copy has the potential to undermine the value and meaning of the original (Cameron et al., 50). Cameron suggests that the work of Walter Benjamin and Jean Baudrillard, for example, aims to "hold established object-centered values in place by posing the copy as a dissent force" (Cameron et al., 51). Thus, the current preoccupation with losing the authentic is based on the fear that digital versions will replace the original objects and that the line between the digital copy and the original will become blurred, posing a direct threat to museum culture and practice and, ultimately, the relevance and purpose of museums in general.

Although the authenticity debate raises many valuable questions, the digital does not have to replace the original. The use of digital media in the museum space does not have to be understood as a threat to the relevance and purpose of art and cultural institutions, but rather as a valuable set of tools that curators and interpretive planners can use to engage new audiences, make their collections more accessible, and enhance educational programming. In fact, one could argue that the relevance of museums is hinged upon their willingness to adopt new digital technologies and leverage modern mobile technology to reach audiences.

In Sonia Livingston's Participation Paradigm, Livingstone suggests a new methodology for researching audiences, one that considers how the changing media "enables or impedes 
participation in society" opening up a new dialogue on democracy, civic culture and civic society, recognizing the significance and current focus on participation (Livingston, 5). Livingstone writes that "the process of participation (and, more widely, of democracy) are increasingly shaped by modern digital networked media" and that this increasing process of participation also suggests that audiences themselves are becoming more participatory (Livingston, 5). Jenny Kidd, on the other hand, posits that institutions are challenged by the Participation Paradigm, not only because they may not have the resources, infrastructure, or technology required to utilize digital participation in an effective way, but also because they face various ethical and philosophical challenges (Kidd, 14).

The aforementioned is true, and digital projects using AR require resources and a budget that most institutions do not have. Correspondingly, art and cultural institutions often lack the internal staff with the tech and programming skills needed to undertake such projects. Barriers to accessing AR technology will likely decrease as AR becomes ubiquitous. Some very recent developments in both Google's ARCore platform and Apple's ARKit app have made it easier and faster for app developers to create new AR experiences. Yet, the actual work still requires a developer to navigate and build out the content in these platforms. Creating a truly unique and meaningful AR experience — tailored to fit a museum's specific needs and content—requires advanced skills in programming, coding, animation and computer graphics, native app development, user interface and user experience design, and, occasionally, expertise in game development software like Unity, for example. 


\section{Design, Technical Challenges, and Purpose}

As previously mentioned, designing and programming an AR app requires a certain skill set. Coding aside, a well-designed user interface and good user experience design are key to the success of any app, regardless of its purpose and function. For museums, these principles become even more significant, as they can greatly impact the usability of the app and, ultimately, the user experience. If the app is not easy to navigate, the interface too cluttered, or the icons unclear, the user will likely be put off. AR apps already come with a unique set of challenges, but a poorly designed app that attempts to integrate AR features is not going to build a case for creating more of these experiences within a museum.

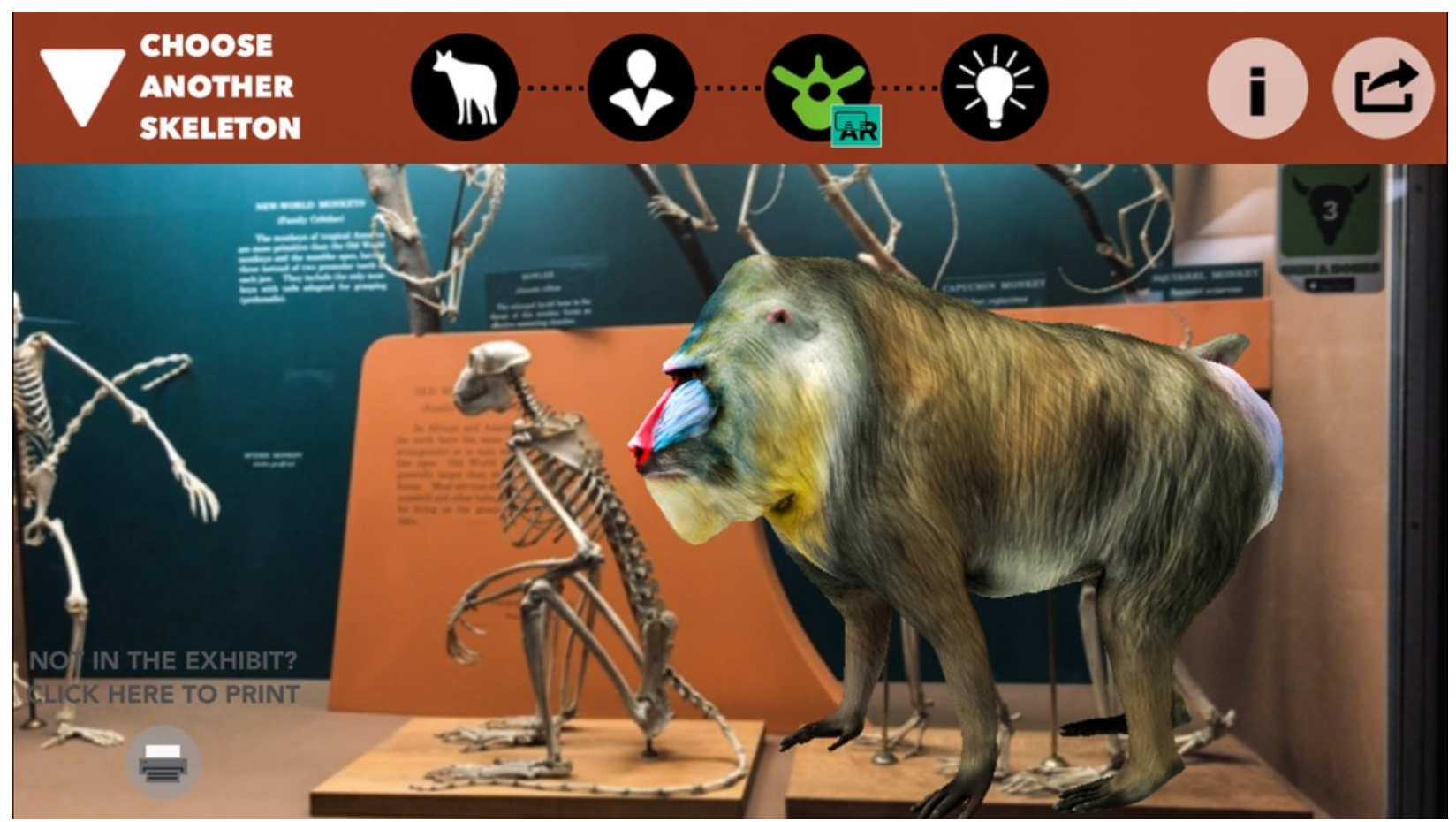

Figure 2. Screenshot of phone interface while in the augmented reality experience using the Skin \& Bones App at the Smithsonian National Museum of Natural History. This image depicts the overlay that appears when the user holds their phone up to an animal skeleton in the Hall of Bones. Courtesy of author. 
On a recent trip to the Smithsonian National Museum of Natural History (NMNH) in Washington, D.C., I had the opportunity to try the Skin \& Bones app. After having tested numerous AR apps, I decided to use this one as an example because I feel it best demonstrates some of the challenges of creating an AR experience for a museum space. Using the app, as well as observing others in the exhibition space use it, provided great insight into what works and what does not. The app offers a guided, interactive tour of the skeletons exhibition with AR features. In addition to bringing the skeletons to life, the app also includes rich media components (videos, text, and narration) that go beyond what is presented in the physical exhibition space. The AR experiences — only available for select objects in the skeleton exhibition — are activated by tapping a button within the app. In some cases, the AR is just an overlay that shows the user how the animal, reptile, or bird looks alive with skin or fur. In other cases, the skeleton comes to life and moves across the frame in the form of an animation. The app does provide valuable additional information, from an educational perspective, but the AR component is not as fascinating as it could be. There is no noticeable signage, aside from one small panel at the beginning of the exhibition that indicates an AR app exists. Although this information is available on the website, visitors are not informed about the app upon entry into the museum. Another challenge is that there are limited museum staff available to assist users; the app itself is not very intuitive and the interface is a bit overwhelming.

Another issue when using the app is that the exhibit rooms are quite small and offer limited distance from the objects when distance is requisite for using the app. I found myself bumping into others while immersed in the experience. Most objects are also cased very far behind glass, which — at certain points — also interferes with the experience and alignment of the image or animation overlay. Space, and how it is used within an exhibition incorporating AR is 
especially important when dealing with works of art or objects that are not protected. It is quite easy to get lost in the interface of your phone during an AR experience and bump into whatever is in front of you if you are not careful. For this reason, any AR experiences within an exhibition space need to have floor indicators that users should not go beyond.

Although the Skin \& Bones app does work to enhance the exhibition experience, the AR feature is not really used to its full potential and the overall design is problematic. There did not seem to be a strong case for why AR was part of the self-guided tour and, as a result, felt a bit trite and gimmicky.

Helen Papagiannis, in her book Augmented Human: How Technology is Shaping the New Reality (2017), identifies a much-needed shift from focusing on the technology of AR, to creating meaningful and compelling content (Papagiannis, 4-5). AR should no longer be just about the technology, but about using the technology in innovative ways to create human-centred and enriching experiences (Papagiannis, 4-5). Papagiannis notes that the next wave of AR experience will focus on context, personalization and interaction. Museums must, therefore, find a balance between creating meaningful and engaging content and utilizing augmented reality technology in innovative ways that go beyond gimmick.

\section{Copyright and Licensing}

In addition to concerns over digital reproductions and authenticity, lack of resources and expertise, and technical limitations, another challenging barrier is the copyright and licensing of collections material. Like any digital projects undertaken by museums and archives, the rights to publish and disseminate digital reproductions of objects and artwork - the same goes for digitally born objects and artwork - becomes a challenge when the institution does not own the rights to 
said objects. In my own research and quest to find a collection to work with, I have found this, above all, to be the greatest barrier. A licensing agreement might allow for a digital reproduction to exist in a virtual exhibition online, for example, but might not allow for it to exist in a digital media experience within an app that would then be accessed through the App or Google Play stores. In my experience, even archives that are able to provide digital reproductions of collections material for a fee seem to be unsure of what type of licensing agreement would be appropriate for digital reproductions that exist in virtual space — within virtual, mixed, or augmented reality apps. For this reason, working with material that is in the public domain is, although somewhat limiting, much easier. That being said, there $i s$ something that will have an impact on these barriers related to digital reproductions, and copyright and licensing, which will be of great benefit to institutions looking to do more with augmented reality - that something is a shift, albeit slow, towards creative commons licensing. ${ }^{\mathrm{vi}}$

\section{Possibilities: AR for Photographic Collections and the Photograph as Image and Object}

The materiality of an image is valuable, thus making its preservation an important concern. Being able to study a photograph as a physical object, as well as an image, is also important. Elizabeth Edwards and Janice Hart in Photographs Objects Histories: on the Materiality of Images, referencing Batchen, have spoken of this importance.

Photographs exist materially in the world, as chemical deposits on paper, as images mounted on a multitude of different sized, shaped, coloured and decorated cards, as subject to additions to their surface or as drawing their meanings from presentational forms such as frames and albums. Photographs are both images and physical objects that exist in time and space and thus in social and cultural experience. They have volume, opacity, tactility and a physical presence in the world (Batchen 1997, 2) and are thus enmeshed with subjective, embodied and sensuous interactions (Edwards and Hart 2010). 
The physical existence of a photograph, however, does not have to be challenged by a digital version of it. Placing digitized photographic objects and archival material within an AR experience and using it to tell a story opens up new possibilities for discovery-based learning. By using image target or object recognition—using the camera's vision on a smart device to recognize a target — and delivering interactive visualizations and layered information to the user, $\mathrm{AR}$ can be used to give new life to photographic material and provide greater context for understanding a photograph, establishing a meaningful connection between the photographic object itself and the greater history and narrative it belongs to. A location-based media experience, for example, can enable an interactive gallery of images within a real-world context at a site of specific historical and cultural significance within a self-guided tour, bringing the content outside the museum walls.

In an exhibition setting, for example, sound bites relating to each exhibited image could be triggered using 2D image recognition, serving as an enhanced, non-linear audio guide- the soundbite is activated by using a smartphone camera's vision to recognize an image target. Meanwhile, additional points of discovery within AR could allow the user to interact with and learn about photographs in different ways. Crowdsourced comments and images related to the photographic material being displayed could pop-up in AR as users navigate through an exhibition. The user might have the option to pinch and zoom into the photograph for more detail as it is being described, or even learn about an object that has been restored through virtual layers. AR pop-ups with text triggered by image targets could reveal additional information about the photograph. Some of these pop-ups could also speak to materiality: How was it made? What can be said about the process used to make the image during that time? What camera did the photographer use? A historical photograph could be brought to life and animated in AR - the 
viewer could actually step into it and take a look around. The possibilities do seem endless in terms of offering alternative viewing experience through an app while also relating the image to its greater context.

Information about the materiality of a photographic object — the process by which it was made, the appearance of recto and verso, and preservation and housing considerations - can be delivered to the user in an AR experience, thereby enhancing the user's understanding of that photograph as an object. Such an application could be useful for archivists and researchers as well. Looking at a photograph and being able to view related images and digital assets from another collection as a virtual layer could serve to educate users about the provenance of a photograph. Information about the photographer, the subject, the cultural, social, and historical contexts during which the print was made, aesthetic choices, and various other interpretations, can serve to enhance the viewer's understanding of the photograph as an image and object.

How is this any different from attaching a QR code to an archival box or sleeve or affixing a code next to a photograph hanging in an exhibition in order to deliver additional information to the viewer? ${ }^{\text {vii }}$ Although QR codes are easy to use, barrier free tools for accessibility, interacting with one is no longer a novelty because they have been in use for so long. Activating a QR code is simply not as exciting or immersive as AR. All photographic objects, prints, and materials have stories behind them. Using AR to tell compelling, immersive, and multi-layered stories presents new possibilities as this medium continues to evolve: "AR is a new communication medium that has great possibilities for extending the human condition, reimagining the way stories are told and experienced" (Papagiannis, 68). Potential applications of augmented reality for photographic collections are explored further through a creative project outlined in the next section of this paper. 


\section{Part II: Creative Project}

\section{A PROTOTYPE FOR AN INTERACTIVE MULTIMEDIA APPLICATION THAT COMBINES AUGMENTED REALITY AND STORYTELLING WITH PHOTOGRAPHS AND RELATED MATERIAL FROM AN ARCHIVAL COLLECTION}

This creative project aims to test various uses of augmented reality for interpreting photographic material and related records in a collection. The project takes the form of a prototype for an interactive, multimedia application that combines augmented reality and storytelling with photographs and related textual records from an archival fonds. The archival material is used to tell the story of a forgotten Nova Scotian writer and photographer, Clara Dennis, and connects her photographic material with the greater history/story to which it belongs. The project also aims to demonstrate how AR can be used to extend situated exhibits of photographs and related archival material. The AR experiences are activated using image targets that are placed physically within an exhibition context. The image targets are either archival photographs, textual records, books, or photographs taken by me. The photographs taken by me are of sites that Clara Dennis also photographed. In this case, I have employed the practice of rephotography to create a relationship between the past and the present- the re-photographed sites serve as more than just image targets and provide a unique context for viewing and understanding Clara's photography. Since the story and experience extend from the photographs exhibited it does not necessitate being at those specific locations - physically—in Nova Scotia.

Each image target activates part of the story in AR and delivers information, soundbites, audio narration, interactive visualizations and additional archival photographs and textual records to the user through an iPad. The app also acts as a self-guided tour and allows the user to 
explore the exhibition in an unconventional way. The curated, self-guided tour, educates the user about the photographs in a way that a traditional gallery exhibition might not, allowing them to make discoveries and interact with the material being shown in a more engaging way.

In part A of the next section, I describe the Clara Dennis fonds, provide background information and historical context and discuss why I chose to work with this material. In part B, I discuss the design process for the prototype, describe the user experience and how the app functions, as well as what technology was used to build it.

\section{Part A: The Clara Dennis Fonds and Related Research}

Clara Archibald Dennis was a Nova Scotian writer, author and photographer. She was born November $24^{\text {th }}, 1881$ in Truro, Nova Scotia and died in Halifax on February $26^{\text {th }}, 1958$, at the age of 76. Dennis attended Mount Allison University, Dalhousie University, and the Halifax Business College, after which she worked for her father Senator William Dennis at the Halifax Herald in the office and as a reporter. Clara Dennis came from a well-educated and prominent family. William Dennis was the editor and proprietor of The Halifax Herald and The Evening Mail. Her mother Agnes (Miller) Dennis, a feminist and educator, was the president of the Halifax Victorian Order of Nurses and president of the Halifax Local Council of Women and held various other notable titles and awards. Following the death of her husband, Agnes Dennis became the president of Halifax Herald Limited. Clara Dennis published many newspaper and magazine articles on Nova Scotia and its people. Most notably, she published three books recounting her travels throughout the province: Down in Nova Scotia (1934), More About Nova Scotia (1937), and Cape Breton Over (1942). Like her mother Agnes, Clara Dennis was a member of numerous organizations. In addition to philanthropic work during the war years and 
working for the Red Cross, she was the first president of the Nova Scotia branch of the Canadian Women's Press Club, president of the Halifax branch of the Canadian Authors Association, a prominent member and vice-president of the Nova Scotia Historical Society, and a member of the Victorian Order of Nurses. In recognition of her contribution to Canadian Literature, Clara Dennis was awarded an honorary doctorate in literature from Mount Allison University in 1938. Until recently, Clara Dennis was somewhat forgotten, as not only a writer, but a woman photographer. In 2005, the Nova Scotia Archives (NSA) created the virtual exhibition The Quest for the Soul of Nova Scotia, highlighting some of her photographs and work. Following the launch of the online exhibition by the NSA, the then Minister of Tourism and Culture Rodney MacDonald, stated in an article in the Halifax Chronicle Herald that "the launch of this online exhibition acknowledges the significant contribution that Clara Dennis's work made to Nova Scotia's documentary heritage" (Halifax Chronical Herald 2005). Although Dennis appears in some articles about her contribution to literature, very little has been written about her photography. In November 2006, her photography work was included in an article in Photo Life magazine titled "Forgotten Photographers," written by Susan Fisher (Fisher, 71). Since then, the NSA has digitized most of her photographs and produced a more comprehensive virtual exhibit called Clara Dennis Tours Nova Scotia, acknowledging the significance of the thousands of photographs she took during the 1930s and 1940s documenting life in Nova Scotia. The value of her documentary photography and the photographic record she produced was not recognized or valued following her death. The lack of recognition Dennis received for her work is unsurprising - women photographers were generally underrecognized during this time, as was the value of photographs within an archive's collection. 
According to the archival description, the estate of Clara Dennis was disseminated following her death and most of her material was either lost or destroyed. What remained of her photographic albums was donated to the NSA in 1981 and 1983 by Christina Shaw of Halifax. The textual records were found in a vault of the Atlantic Trust in Halifax in 1989 and were then donated to the archives to complete the fonds. Some of Dennis's photographs are also part of the Nova Scotia Museum collection, specifically those containing images of the Mi'kmaw. The Clara Dennis fonds at the Nova Scotia Archives consists of a variety of materials that demonstrate Dennis's once active career as a writer, researcher, reporter, and documentary photographer. The fonds includes her personal notebooks containing research on Nova Scotia, Cape Breton, the Mi'kmaw, and various other subjects, personal correspondence and business exchanges, newspaper clippings, booklets and ephemera, drafts of her writing for published and unpublished articles, and a large collection of photographs.

The photographs were originally donated to the archives in the form of albums, likely compiled by Dennis herself. In 1981, 11 albums of photographs were donated, with an additional 3 albums donated in 1983. Some of the albums were water damaged prior to acquisition, therefore, most photographs were removed from the albums and rehoused for preservation. The photographs are all small, silver gelatin prints with some variation in size, but the majority are around $14.5 \mathrm{~cm} \times 9 \mathrm{~cm}$. The fonds does not contain any of her original negatives or photography equipment.

According to the archivists at the NSA, there are no digitized copies of what the albums looked like, but some of the provenance has been retained in the form of photocopied album pages as part of a finding aid, which provides some insight into how she arranged her photographs and inscribed the pages. By looking at the photocopied album pages and the 
inventory list, it is evident that Dennis had her own cataloguing system for her photographs. Among the textual records is a list in her handwriting that matches some of the subject headings and numbering system on the album pages. It seems she arranged each album according to subject or location and used roman numerals. Looking at the list of subjects that correspond with the albums provides an understanding of just how extensively she documented the province of Nova Scotia and the East Coast of Canada, through photography. Subjects include: counties, towns, cities, islands, homes, churches, monuments, bridges, beaches, rocks, bodies of water, waterfalls, the ocean, people, communities, animals, mining, fishing, quarries, Cape Breton, New Brunswick, Gaspe, Mi'kmaw communities, and various others.

In addition to documenting her travels through photography, Dennis also kept many personal notebooks containing research notes, interviews, and information that was used in her published articles and later in her three books about Nova Scotia. The majority of the information contained in the notebooks is historical or pertains to specific communities she visited and people she met. A significant section, however, includes interviews she conducted with Mi'kmaw chiefs, elders and community members between 1923 and 1929 and notes she made on Mi'kmaw beliefs, social life, and customs. Although most of these notebooks are in very poor condition and the writing is illegible or difficult to read, some have been transcribed. According to the transcribed records associated with the notebooks, several of Dennis's notebooks were transcribed by Ruth Holmes Whitehead, a historian and ethnologist who worked for the Nova Scotia Museum. ${ }^{\text {viii }}$

Although Dennis has been recognized for her photographs and writing on the Mi'kmaw, her documentation would have come from a settler colonial perspective, therefore, I do not feel it is appropriate for me to include this part of her work in this digital project. 
Access to the original Clara Dennis photographs is restricted for preservation reasons, as most have been digitized and made available on the NSA website. Over 2500 of her prints are available via the archive's website, but the majority of the textual records are not. I was able to physically view one additional box of prints that had not been digitized; this box contains photographs of waves, water scenes, rivers, waterfalls, roads, and rocks. Since most of the textual records have not been digitized, I was also given permission to view those. This process, and the research conducted at the Nova Scotia Archives, allowed me to gain a better understanding of what the fonds contains and how the photographs and textual records relate to one another, as well as how the accession records, inventory, and finding aids are organized.

\section{Why Clara Dennis?}

In selecting a grouping of archival material to work with for the prototype, I considered multiple criteria: the material had to be accessible, digitized already or I would need to have the option of having it digitized, contain both photographs and textual records, and could be linked to a larger narrative.

Through both images and words, Dennis was an incredible storyteller. Hailed during her time as being Nova Scotia's first woman travel writer, Dennis explored every inch of her home province of Nova Scotia, camera and field notebook in hand. An adventurer and explorer of places, Dennis also appeared to take interest in documenting the lives of those living beyond the big cities in small or marginalized communities. An article written about Clara Dennis in the Halifax Chronicle Herald on February $17^{\text {th }} 1958$, the day after her death, states that "her unique presentation of the story of Nova Scotia was made possible, however, only by years of itinerant life in places remote from the busy centres of commerce and of learning" and that " her books 
present much previously unknown material about places and people neglected, not only in the wider arena of the whole province, but precisely where she had gathered it" (Halifax Chronicle Herald 1958).

Her letters of correspondence suggest that she respected those she photographed and wrote about, and often maintained contact with the people she met travelling. Dennis documented Nova Scotia's built and natural environment in great detail, photographing everything from bridges and roads, to waves in the ocean and even specific rock formations - a short biographical article written about her in 1952, indicates she was also a member of the Dawson Geological Club of Dalhousie University. Although it is important to recognize that her writings and research are very much a product of their time, it is evident that Dennis was interested in telling genuine stories about all people and places in Nova Scotia from an optimistic perspective.

Clara Dennis was an intrepid woman for her time. She liked cars and travelled Nova Scotia by motorcar at a time where there were very few female motorists. Several of her photographs in the fonds feature her car either on a car ferry, along a road, or at the foot of a mountain. What piqued my interest in Dennis, however, was an article she wrote for Canadian Motorist magazine in 1929 titled "Into the North of Cape Breton by Motor." Dennis was the first woman to drive over Cap-Rouge by motorcar on a new road the government was building around the Northern part of Cape Breton island. It was by no means the paved road that it is today, and at that time, the old road over Cap-Rouge was believed to be the most treacherous. The adventurer she was, Dennis made it her goal to travel the road by motorcar as far as it had been built to explore the Northern part of the island and the communities that lived there. 
"The attention here will be directed to the hitherto almost unknown north of the island. Unknown because until just recently it has been inaccessible except by boat and by dog team. A mountain range has shut it off and while the world rushed on with the speed of the airplane, the automobile and the electric and steam railway car, the inhabitants of these villages pursued their leisurely way on foot, visited only on rare occasions by those who came by boat or braved the mountain trail on horseback or with dogs" (Canadian Motorist 1929).

I was also drawn to Clara Dennis's story because, in some ways, her penchant for exploration and her approach to documentary photography paralleled my own. I noticed a similarity in the way she extensively documented her travels and encounters through photography and her genuine interest in telling stories of smaller, underrepresented communities and places, as well as her keen interest in documenting the natural and built environment. Dennis's eagerness to spend time with people, get to know them and create a photographic and written record of their lives based on relationships also resonated with me. After digging through the archives and spending a lot of time looking at her photographs, I realized that I had already photographed many of the same places — with the same level of detail—on my own travels throughout Nova Scotia; the relationship between the past and the present was already there, through both of our images. Given this, I felt that I could effectively go and re-photograph some of the places she travelled to in order to create the image targets for the exhibition. The AR experience is still site-specific, but the story and experience extend from the photographs exhibited and does not necessitate being at those specific locations - physically —in Nova Scotia. 


\section{Part B: Research and Design Process}

In the following section I define the structure and design of the project, and then break it down into component activities, which include five stages: compiling the research, organizing the research and deciding what material to use, media production, designing the prototype, and building the AR experience and proof of concept.

\section{Compiling the Research}

I began the research process by looking at the scope of the Clara Dennis fonds at the NSA and developing an understanding of how the archival material in the fonds is organized, and subsequently determining how the photographs and textual records are related. Following the initial research at the NSA, I looked for additional published information on Clara Dennis, as well as any newspaper articles she published for the Halifax Chronicle Heraldavailable on microfilm at the Halifax Central Public Library. I acquired and read the three books Dennis published on Nova Scotia to get a sense of how she documented and wrote about her travels. Each book reads like an elaborate travel log and is organized into chapters/sections according to location and subject matter; this was useful, because I was able to match locations listed in her books with images from the fonds, also grouped by location. The books also served as a means to understanding how her photography was used to complement and enhance her written work. Finally, I attempted to get in touch with some of her living relatives in Nova Scotia in order to determine if more of her work could be found within a family member's personal collection, but this proved to be too difficult with the limited amount of time I had for the research process. 

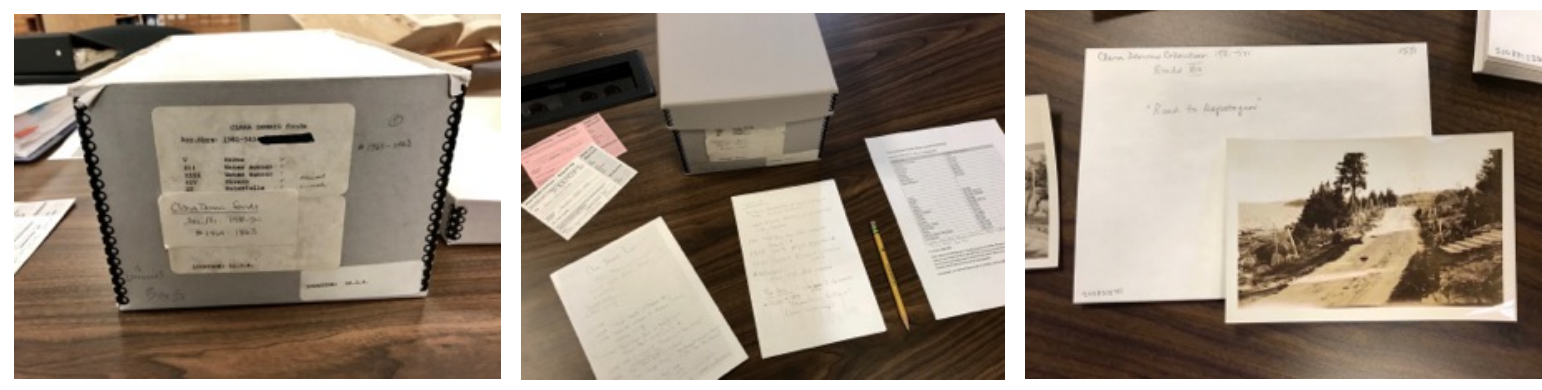

Figure 3. Three images showing the research process at the Nova Scotia Archives. Archival material seen is from the Clara Dennis Fonds.

After compiling the research, I began making image selections based on subject matter and location, acquired the digitized versions and then grouped them accordingly. Following that, I selected material from the textual records and submitted a request to have them digitized. Since the majority of the textual records had not been digitized, I was given the option to take photographs of the material myself or have it scanned. Although having the material scanned was preferable, I opted to photograph the material myself to reduce costs. Permission to use the digitized material was granted by the archive with the understanding that it remain part of a digital media project for graduate studies research and thesis work only.

It seemed unlikely that Clara Dennis made any audio or film recordings herself and relied primarily on her notebooks and camera for recording events, observations and conversations. Given this, in addition to thoroughly reviewing all of the material in the fonds, I sourced any related sound and moving image assets that could be used to help tell the story; this included looking at the Helen Creighton collection for audio recordings of people singing or telling stories and film footage of some of the places in Nova Scotia Clara Dennis travelled during the 1920s1940s. ${ }^{\text {ix }}$ Since I had already determined that I would be focusing on her travels throughout Cape Breton Island and the journey by motorcar to Cap-Rouge for the prototype, this aided in narrowing down my search within the sound and moving image archive. 
The final step in the research process involved reviewing local history pertaining to the locations that Clara Dennis documented. I looked at Cape Breton Island and then, more specifically, Cap-Rouge and Chéticamp during the time Clara Dennis travelled the island. In addition to local history, I looked for road maps of Cape Breton Island before the Cape Breton Highlands National Park was established in 1936 and the road was still a gravel/dirt road. The next step was to organize the material and find linkages to help shape and tell the story.

\section{Organizing the Research and Making Selections}

The second stage of the project included organizing the research, narrowing down the selections of digitized material and crafting the narrative structure. This process involved the creation of multiple visual mind maps and then deciding what material would serve as image targets, what would be displayed in AR and how the additional textual records and multimedia assets would be integrated. I decided on the following categories for organizing the material within the prototype application: biographical information on Clara Dennis, books by Clara Dennis, letters and other correspondence, field notebooks. In addition to these four categories, I created three individual stories based on counties she photographed and wrote about in her books: Cape Breton Island, Tancook Island, and Lunenburg County. Although Dennis photographed and wrote about almost all 18 counties in Nova Scotia, for the purposes of this project I selected three locations as samples and focused on Cape Breton Island for the prototype. These selections were made based on how compelling I found the related images, how well they represented her work as a documentary photographer and travel writer, as well as how easy it would be for me to go and re-photograph these locations and produce any additional media assets. 
Prior to beginning the prototype design process, I created multiple visual mind maps that organized the archival material and photographs according to the categories I had established. The mapping process allowed me to visualize what the user flow and navigation would be, determine what images or objects would serve as image targets for the AR activations, as well as where audio, video, animations, and 3D models might be integrated into the AR experience.
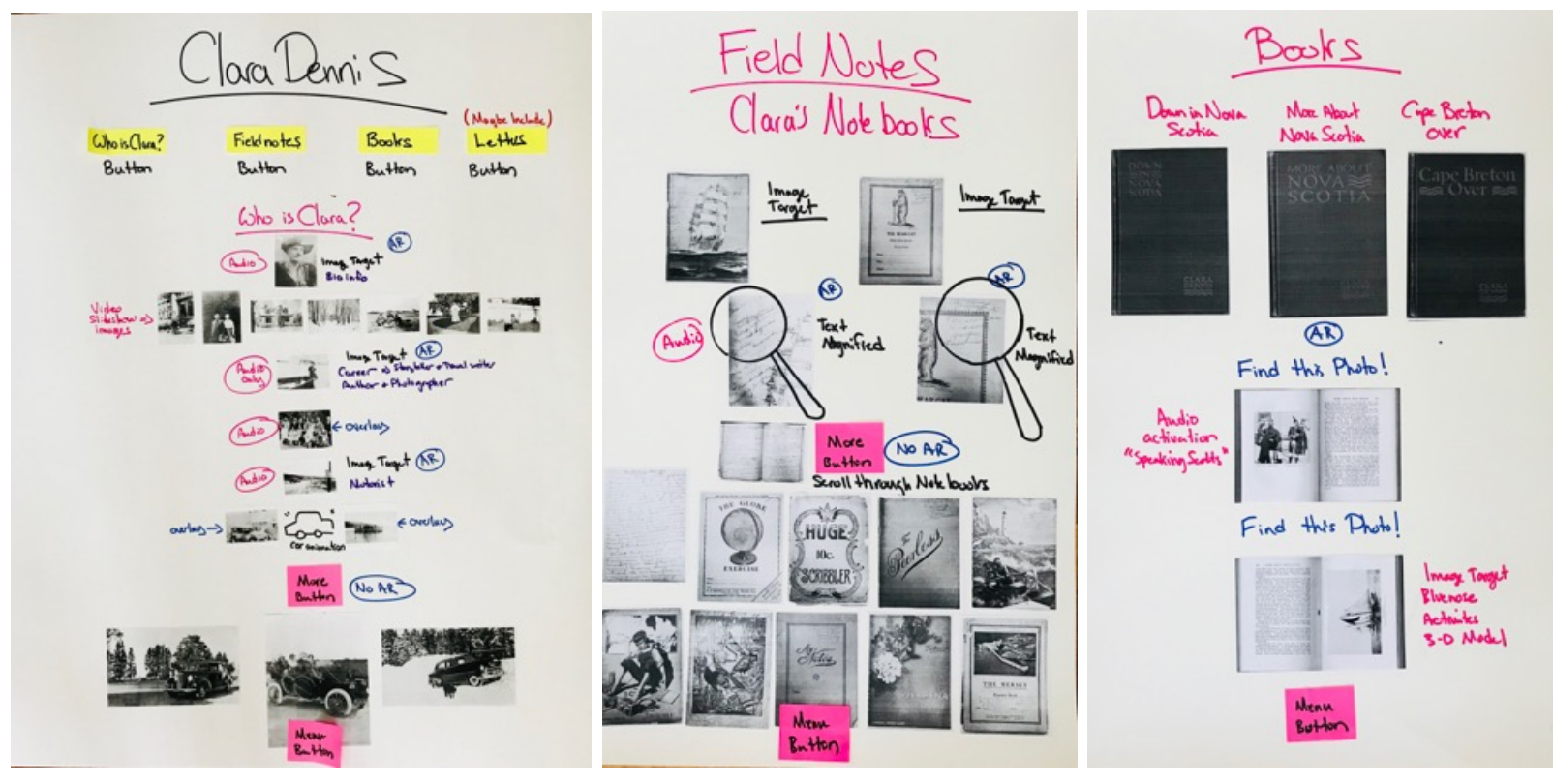

Figure 4. Samples of the visual mind maps created during the organization stage of the project.

\section{Media Production}

The media production process began with making a production list of required media assets and then creating those assets by re-photographing selected sites, collecting video footage, and capturing audio. Following this, the media assets were edited using software such as Final Cut Pro, Adobe Photoshop and Lightroom and then formatted for import into Unity.

In order to produce image targets for the project that would also serve to enhance the narrative, I selected specific sites to go and re-photograph. The re-photography process took me 
to Cape Breton Island, at the eastern end of Nova Scotia. The Cabot Trail, which is now a paved road, encircles the island and follows rugged coastline, passes through forests and borders the Cape Breton Highlands National Park. At the time Dennis travelled Cape Breton Island, the newly built road was made of dirt and gravel which made travel by motorcar possible but challenging. Dennis photographed and wrote about the entire island and all of its small towns and communities. For the purposes of this project, however, I focused on the West coast of the island and Dennis's journey to Cap-Rouge, her exploration of the town of Chéticamp and its Acadian residence, and sections of the Cabot Trail from Inverness County to Pleasant Bay.

The original road to Cap-Rouge that Dennis travelled at the time she wrote the article for Canadian Motorist Magazine in 1929, is now an eight-kilometer hiking trail in the Cape Breton Highlands National Park called Le Vieux Chemin Du Cap-Rouge Trail. In order to produce both image targets for the exhibition and additional images for the AR prototype, I hiked and rephotographed the Cap-Rouge trail, photographed scenes along the Cabot Trail, and also photographed locations and people in Chéticamp. I decided to include Chéticamp in the story because of an interesting link between the old Cap-Rouge settlements and the Chéticamp area. ${ }^{\mathrm{x}}$
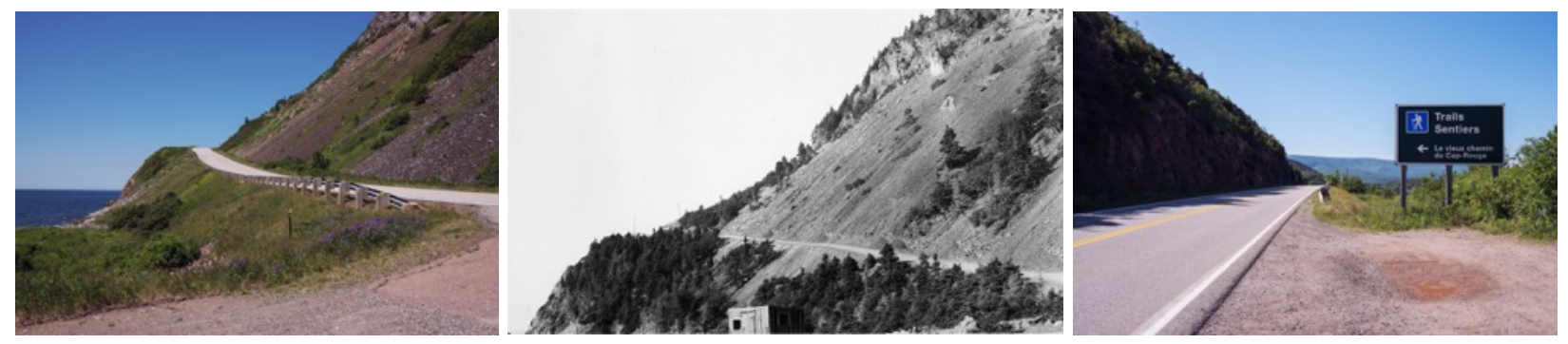

Figure 5. Left: Photograph of the current road leading up to the Cap-Rouge hiking trail on Cape Breton Island, taken by the author. Centre: Photograph of the old road ascending Cap-Rouge on Cape Breton Island, taken by Clara Dennis, Courtesy of the Nova Scotia Archives. Right: Photograph of the head of the Cap-Rouge hiking trail in the Cape Breton Highlands National Park, taken by the author. 
Additionally, I re-photographed sites on Tancook Island, as well as throughout Lunenburg County to be used in the other two stories featured in the prototype.

During the research process, I selected text from Clara Dennis's articles, books, manuscripts and correspondence in preparation for writing a short audio script to accompany the AR events. Some of the audio recordings are narrative; they complement the material activated in AR and educate the user about Clara Dennis, as well as the places she wrote about and photographed. In other instances, the audio recordings are direct readings from her books and articles, allowing her voice as a writer to help tell the story. Dennis's writing evokes a strong sense of place and listening to her words in combination with viewing her photographs provides the user with a richer storytelling experience. Due to a limited budget and resources, however, I used my own voice to do the narration and play the character of Clara Dennis. Ideally, the narration and the character of Clara Dennis would be distinct and recorded professionally by voice actors.

\section{Designing the Prototype}

The prototype design represents what the multimedia AR application would look like if I had the resources to develop the application professionally and includes visual representations of what the AR activations and events would look like through the interface of the app. The prototype was designed and built using Adobe XD with some design elements and image assets created in Adobe Photoshop CC. The prototype is currently designed for use on an iPad.

My goal at this stage was to focus on the experience design of the app by aiming to integrate the overall concept of the project across all of the design elements - from usability and function to aesthetics and space. I felt that it was important to have one consistent visual 
language across all of the touch screens, such as the presence of a simple pop-up menu and return home button, for example, to help orient the user within the experience.

Taking into consideration what I learned while testing other AR museum apps, as discussed in Part I of this paper, I established the following set of criteria before beginning the design process: the app should have a clean and simple interface that presents the images and archival material exhibited in the best way possible with minimal clutter along the perimeter. The design should incorporate a simple colour palette and an aesthetic that does not detract from the content. Icons and buttons should be obvious to the user and standard symbols should be utilized. A simple pop-up menu with instructions on how to use the app and a button that redirects to the home screen and an index to help the user understand what the icons mean should be accessible at the bottom of each touch screen. Regarding the content, the image targets should not be random, but contribute to the story in a meaningful way, as well as provide context for understanding the archival photographs and related records. Most importantly, however, the content that is made available through the AR activations must add value to the story and experience and go beyond gimmick.

With the aforementioned criteria in mind, I designed the prototype around the categories/groupings of information I had established during the research and organization process. 

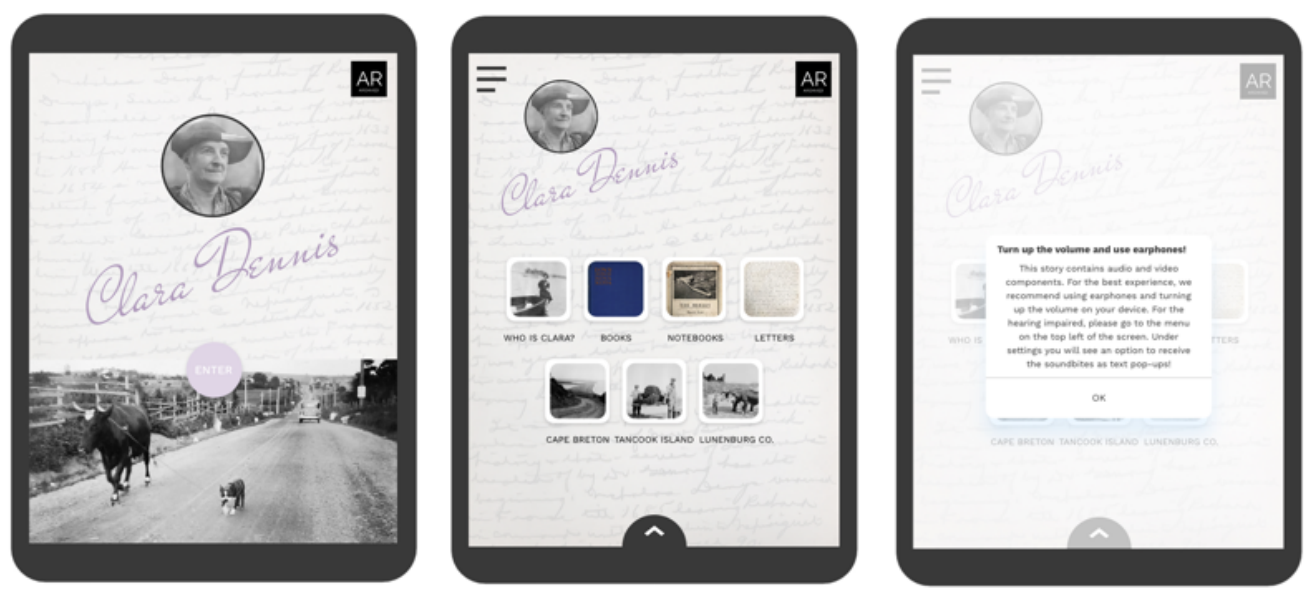

Figure 6. Left: Launch screen of the prototype design created in Adobe XD. Centre: Home screen of the prototype design created in Adobe XD. Right: Pop-up message in the prototype design created in Adobe XD prompting user to use headphones and turn up the device volume.

The home screen currently has seven buttons. Each button activates part of the story and allows the user to learn about Clara Dennis and her career as a writer and photographer by interacting with archival content from the Clara Dennis fonds. Upon selecting a button/category, the user is immediately prompted to use headphones and turn up the device volume. The pop-up also tells the user that transcriptions of the audio clips are available for those who are hearing impaired. After acknowledging the prompt, the user is then given instructions to look for a specific photograph in the exhibition to activate an AR event and begin the story. A similar action is repeated for each category upon tapping the button. 


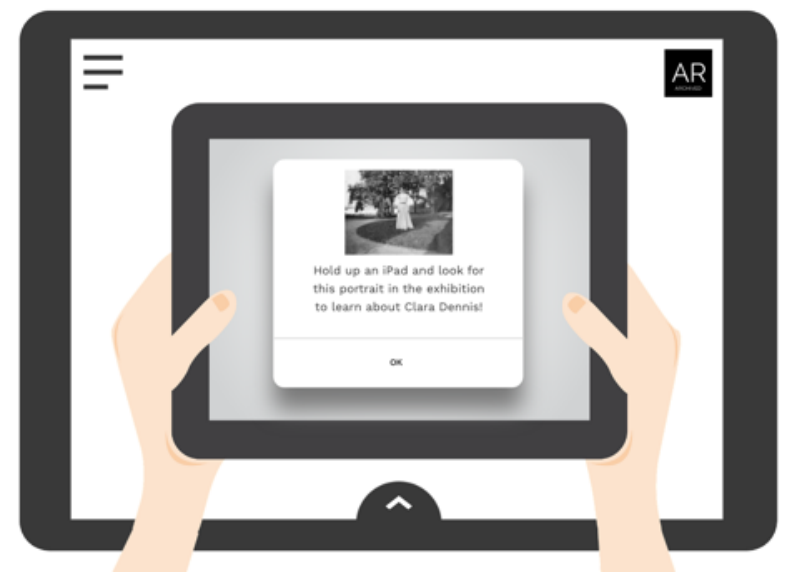

Figure 7. Screen from the prototype design created in Adobe XD showing the instruction screen and related pop-up. The screen tells the user how to activate the AR experiences by finding an image target.

Two key features of the app design are the hidden pop-up menu and the icons that appear throughout the experience when audio, video, or additional information becomes available to the user. The pop-up menu is accessed by tapping the tab on the bottom of the screen and is accessible on all screens throughout the app. The pop-up menu has four icons: a home button that will take the user back to the main menu/home screen, a map that tells the user where they are within the exhibition and storyline, a help screen that provides more detailed instructions on how to use the app, and an info menu that tells the user what each icon means and informs them of any actions required upon seeing the icon. During an AR event, a sound icon appears if there is an audio component to the experience that is triggered upon activation- the icon can be tapped to turn the audio off for that event, if desired. Similarly, a video icon appears when there is a video overlay, a music note icon appears when there is a music clip or soundbite, and an image icon appears when there are multiple images that appear in augmented reality. The image icon will appear red when additional digital records or images are available to view and relate to that part of the story. The red icon can be tapped to access the additional assets. If the user has 
changed the settings to receive the audio clips as text, the audio icon will appear as a text icon instead.
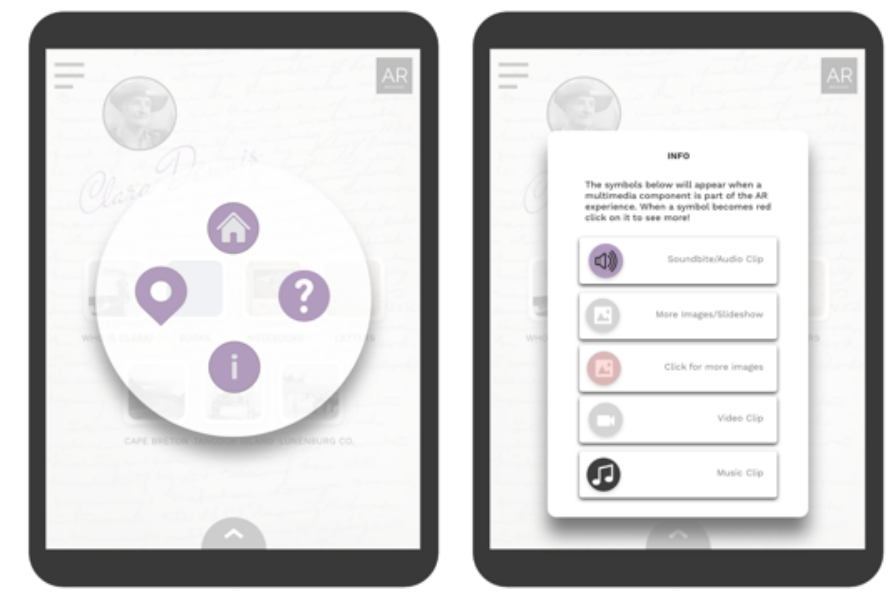

Figure 8. Left: Hidden pop-up menu in the prototype design created in Adobe XD. Right: When the info button is selected from the hidden pop-up menu an icon legend appears.

When the user selects the "Who is Clara Dennis" button, they are prompted to begin the story by looking for an archival photograph of Clara Dennis - the first image target. In this instance, the AR event is an overlay with a series of related archival images that fade in and out of the image target. An audio clip begins upon activation and accompanies the photographs providing the user with biographical information on Clara Dennis. In the bottom (viewer's right) corner a floating label appears with the image overlay and includes information about the photograph such as who the photographer was, the image title or description, dates, as well as any known information about the photograph's materiality_in this case a silver gelatin print. The label can be tapped and enlarged, pausing the sequence of images and allowing the user to read the label in greater detail. A second tap reduces the label back down to size and continues the sequence. This is a repeated action and the label appears for each archival image overlay 
throughout the experience. This label activation could potentially be tailored to the user according to what type of information they would be interested in receiving or personalized by other factors like age or interests.
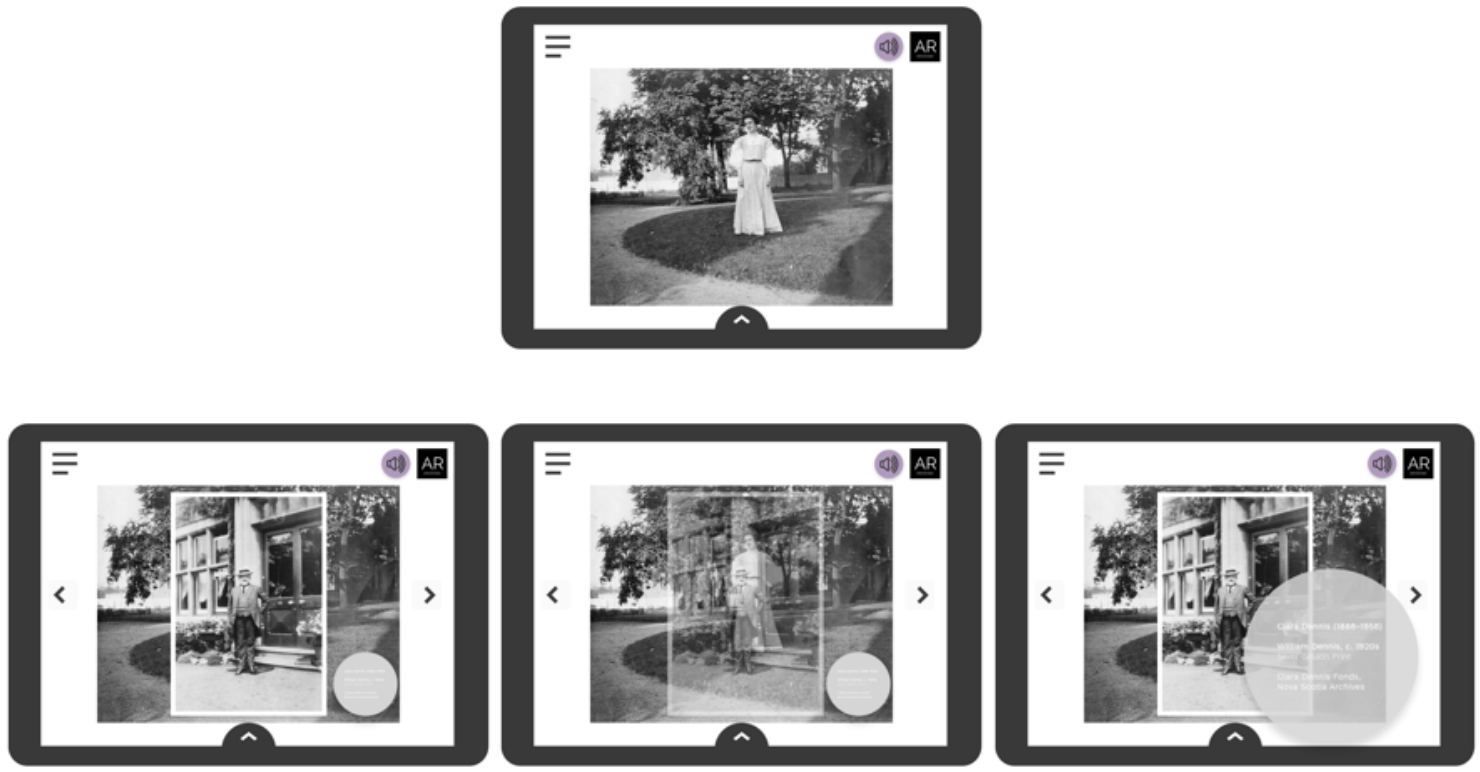

Figure 9. Interface of the app prototype created in Adobe XD: what the user sees during an $\mathrm{AR}$ activation holding the iPad in front of an image target. Also shown is the information/exhibition label activation.

The second image target activates another overlay with an audio clip that tells the user about Dennis's career as an author and writer. The user can return to the main menu at any time and select another category.

Upon tapping the books button, the user is prompted to select one of three books Clara Dennis published and interact with the physical object—each book has a different AR activation. In the book Down in Nova Scotia, a photograph taken by Dennis of the surf after a storm becomes a video overlay with an audio recording taken of the Atlantic Ocean in Nova Scotia at the same location. In the book More About Nova Scotia, the user is able to activate a 3D model 
of the historic tall ship the Bluenose and an accompanying audio clip by holding the device over a photograph Dennis took of the Bluenose ship at sea. In Cape Breton Over, a photograph of a 'Scottsman' playing the bagpipes activates a soundbite of bagpipe music from Cape Breton Island, recorded during roughly the same time period the photograph was taken—sourced from the Helen Creighton collection at the NSA. The front cover of each book, a map of Nova Scotia, activates a car animation overlay and tells the user about Dennis's enthusiasm for motorcars. By touching the 3D model of the car, the user is able to see additional photographs that Dennis took of various other cars. Ideally, the car animation would be designed as an exact replica of the car she drove. The static existence of a photograph printed in a book is thus changed by an AR activation that brings it new life within the story.
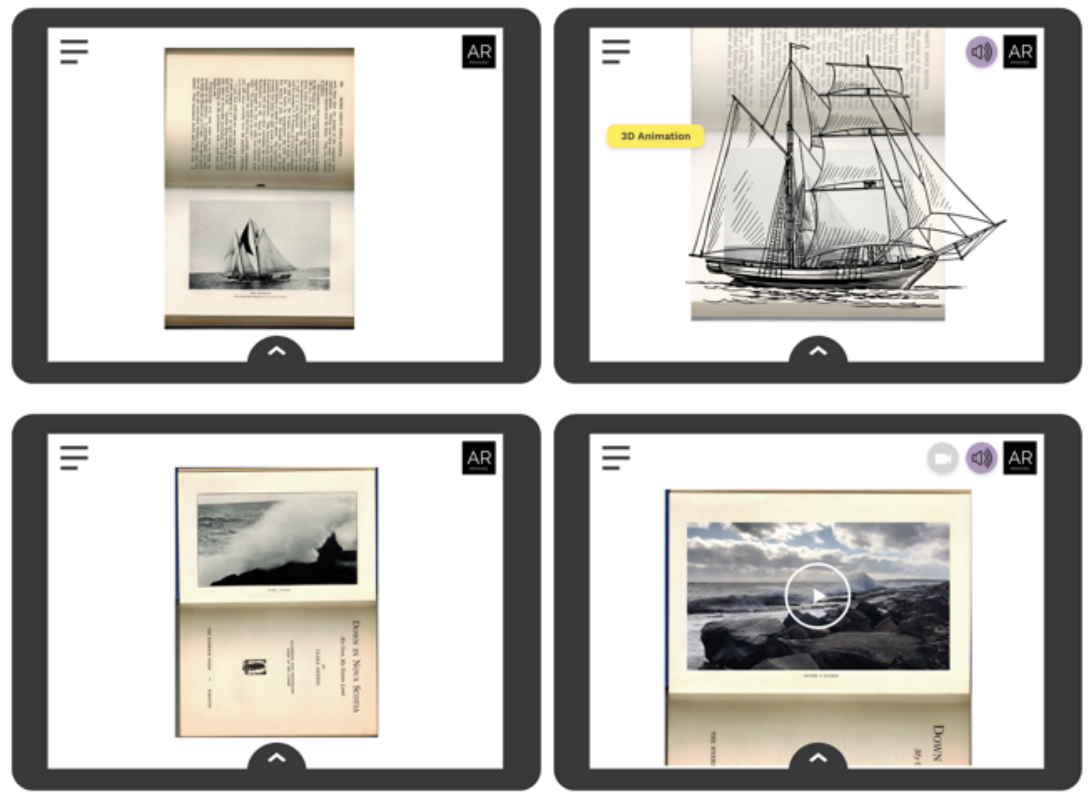

Figure 10. Interface of the app prototype created in Adobe XD: representation of what the user sees during an AR activation holding the iPad over photographs in books published by Clara Dennis. Top: AR event showing a 3D model of the Bluenose Schooner, activated by a photograph of the Bluenose Schooner from the book Down in Nova Scotia. Bottom: AR event showing a video overlay, activated by a photograph of the Atlantic Ocean after a storm from the book Down in Nova Scotia. 
Dennis wrote on the covers of most of her notebooks - primarily notes about the subjects and locations contained within. Interacting with Dennis's notebooks activates a magnifying glass in AR, enhancing and enlarging the text. The magnifying glass can be touched and moved around to examine writing on the covers in more detail. This AR effect is meant to simulate interacting with the physical object, allowing the user to take a closer look at the object and make their own discoveries. The additional objects/images button appears again and allows the user to view pages from the inside of her notebooks. This magnifying effect could also be applied to viewing historical photographic prints in more detail, for example.
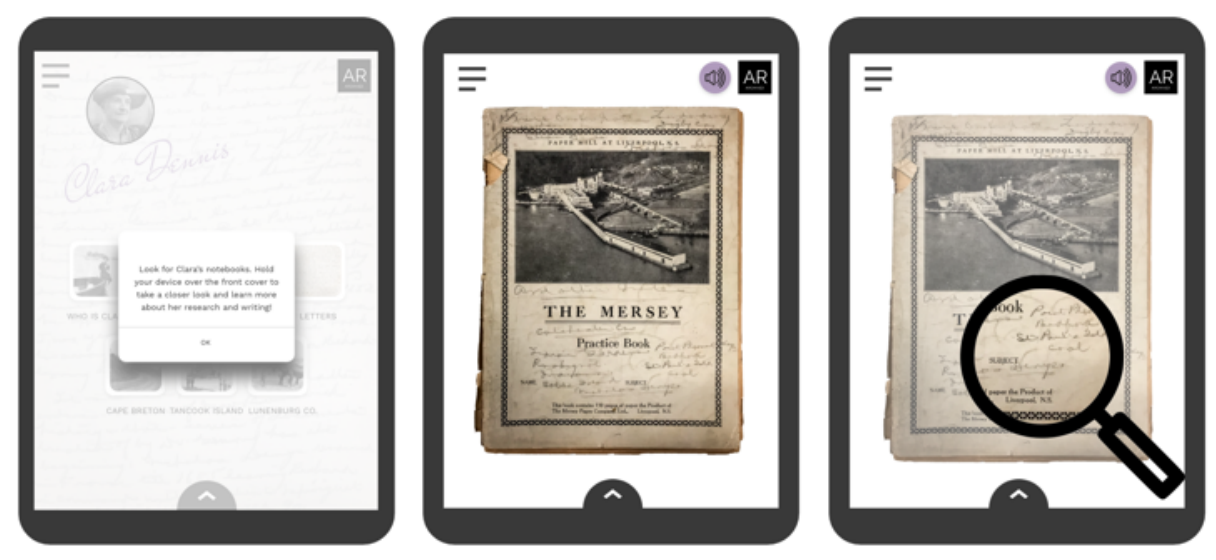

Figure 11. Interface of the app prototype created in Adobe XD: representation of what the user sees during an AR activation holding the iPad over one of Clara Dennis's notebooks. Shown here is the AR magnifying glass event.

The letters button prompts the user to find an envelope addressed to Dr. Clara Dennis. The envelope activates an AR overlay of a writing animation. The user sees Clara Dennis writing a letter and hears an audio recording of Dennis speaking. By pressing the photo icon, the user is able to browse through a gallery of additional letters and correspondence. Many of the letters found in the Clara Dennis fonds are exchanges with the subjects she photographed and wrote 
about or people she visited while travelling; they make a valuable contribution to the story and to understanding her work.

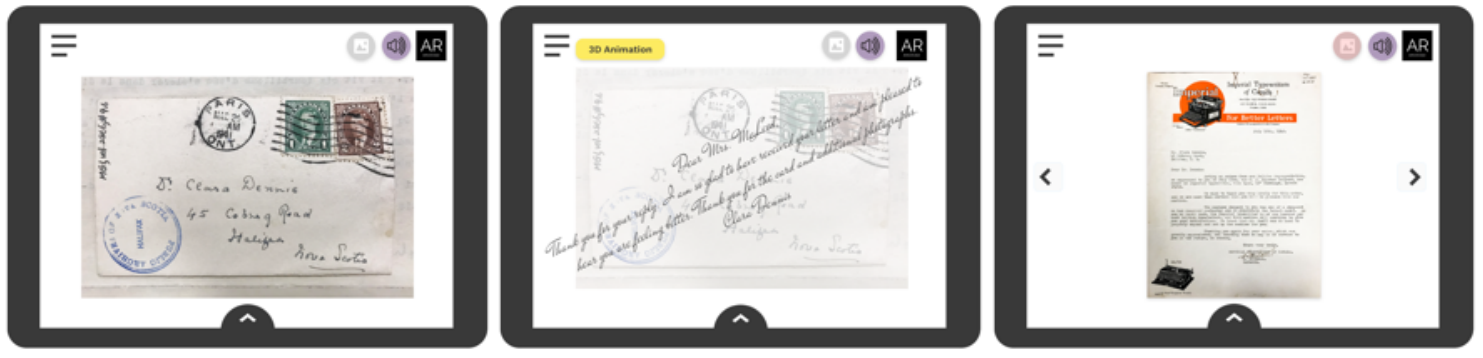

Figure 12. Interface of the app prototype created in Adobe XD: representation of what the user sees during an AR activation holding the iPad over one of Clara Dennis's pieces of correspondence. The AR event shown here is an overlay of a writing animation and additional letters that the user can scroll through.

\section{Individual Stories: The Cape Breton Story}

After learning about Clara Dennis's family life and career, the user can return to the main menu and select a specific story. There are currently three stories in the prototype: Cape Breton, Tancook Island, and Lunenburg County. Each story takes the user on a different trip to an area of the province that Dennis wrote about and photographed. For the purposes of this prototype only three stories have been included, but the app could potentially accommodate more stories to reflect the scope of her travels and work throughout Nova Scotia. In the Cape Breton story, for example, the user learns about Dennis's trip through Cape Breton Island by motorcar, the article she wrote for Canadian Motorist magazine about her ascent of Cap-Rouge, as well as all of the small communities she visited and people she met along the Cabot Trail. The story is told through a series of AR activations, where the image targets are either photographs she took or the re-photographed sites. The story includes audio narration, the voice of Clara Dennis expressed through passages from her book Cape Breton Over and soundbites of Acadian, Gaelic, 
and Scotts music — sourced from the NSA Helen Creighton collection — and activated in AR; the audio clips enhance the story, create a sense of place and provide context for understanding the images. In the following section I will discuss how the Cape Breton story was built out as an AR experience and situated exhibition as a proof of concept.

\section{Building the AR Experience and Proof of Concept}

The project was built using Unity and the Vuforia plugin, as well as some basic custom C\# scripts. Final Cut Pro, Photoshop, and Adobe After Effects were used to edit the multimedia content. The 3D models of the motorcar and tall ship were sourced from the unity asset store and altered to fit the experience.

Since building out the entire project in AR would require time and resources I did not have, I opted to build the POC using only Clara Dennis's story about Cape Breton. The POC does not reflect any of the UI design concepts seen in the prototype design and uses the basic Unity/Vuforia interface. It is thus only intended to demonstrate some of the AR activations and experiences outlined in the previous section. With greater financial resources, the POC could be taken further and the AR app fully developed according to the prototype design. Although the

app was designed specifically for the Clara Dennis story, the design could easily be applied to a different set of material from another collection; this would potentially make it a scalable storytelling platform that includes AR activations. 


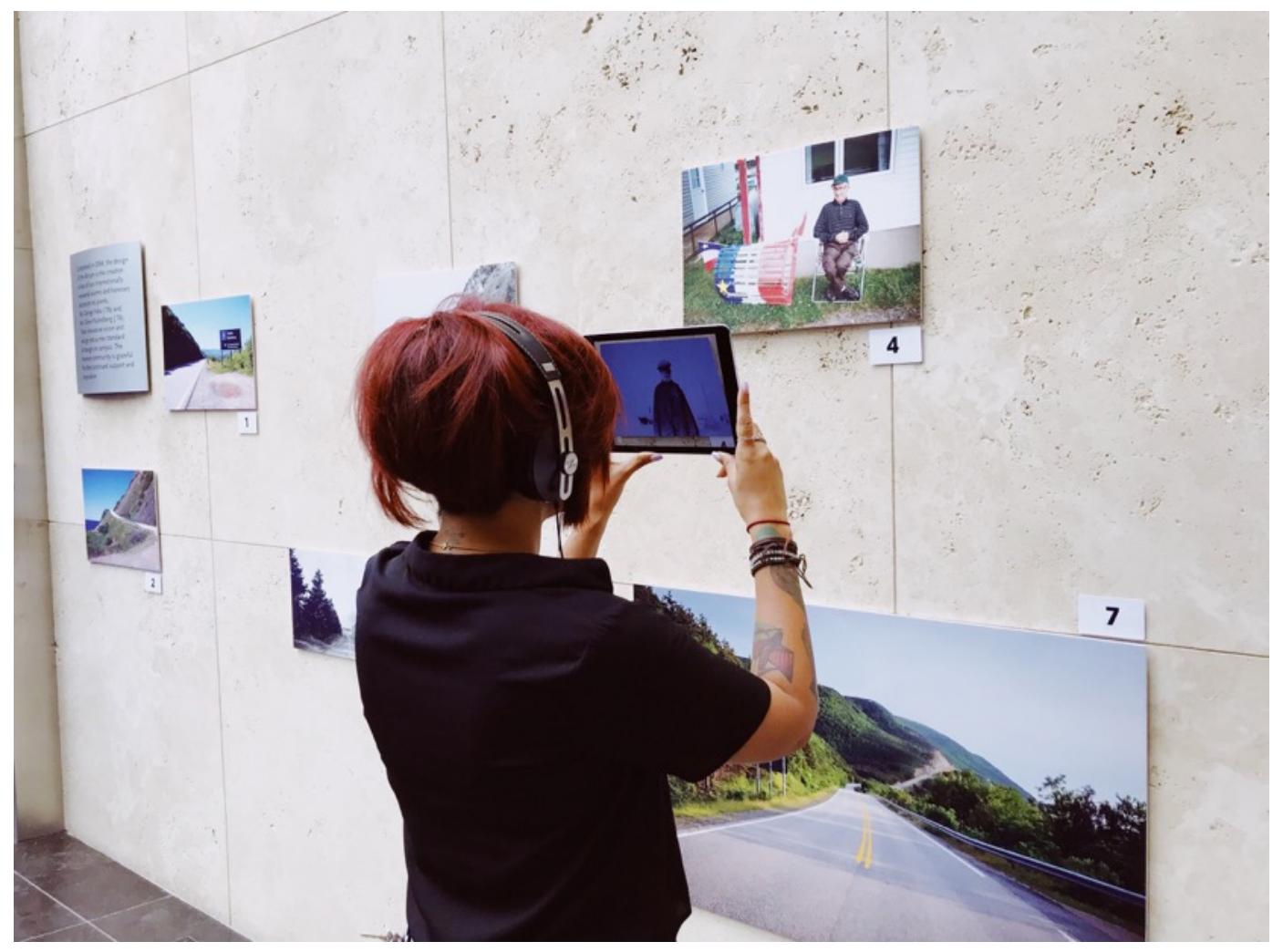

Figure 13. Photograph of an individual engaging with the onsite exhibition and testing the AR prototype at the MDM Showcase. Photograph taken by the author.

The purpose of presenting this work in the form of an onsite exhibition is twofold. The first, is to demonstrate how augmented reality can be used to extend situated exhibits of photographic material within an exhibition space. The second is specific to the story itself. Although it would have been interesting to take the user on a trip throughout Nova Scotia to follow in Dennis's footsteps in the form of a location-based experience, that was not possible. Given this, I decided to employ the practice of re-photography to bring Nova Scotia to Toronto. The Image targets included several photographs from the Cape Breton story, the three books Dennis published, as well as a few smaller reproductions of her photographs in the form of 2D prints. My goal was to demonstrate how different materials could be used as image or object targets while simultaneously being an important part of the story. In this case the image targets 
that activate the AR events are not meaningless but instead contribute to the overall narrative and provide context for understanding the photographic material and related archival records.
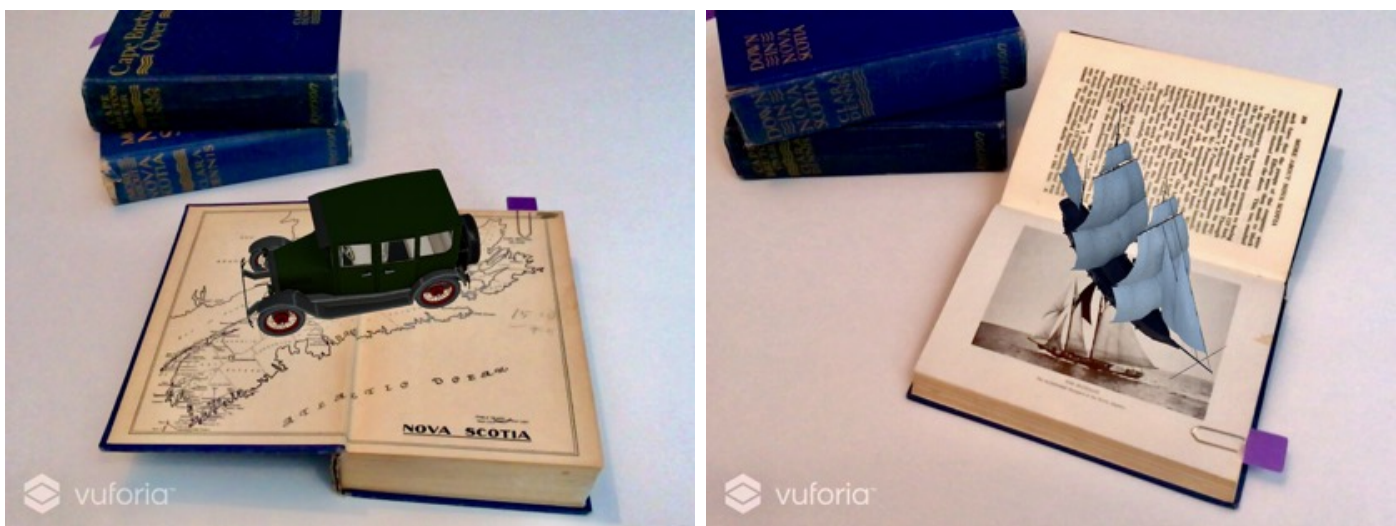

Figure 14. Screenshot of what the user sees during an AR activation. Left: 3D model of Clara Dennis's car appears on top of a map of Nova Scotia in the front cover of one of her books. Right: 3D model of the Bluenose Schooner appears on top of a photograph of the Bluenose in Clara Dennis's book More About Nova Scotia.
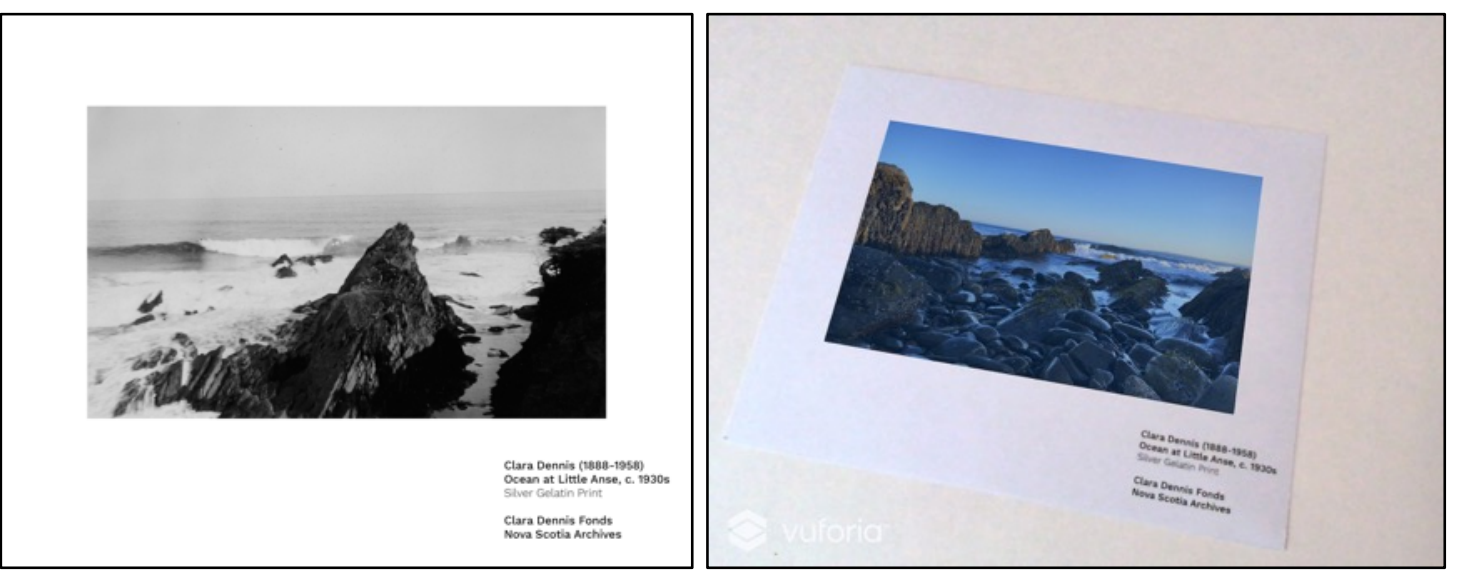

Figure 15. Left: A printed reproduction of one of Clara Dennis's photographs found in the Clara Dennis Fonds at the Nova Scotia Archives. Right: Screenshot of what the user sees during an AR activation: a video overlay of the Atlantic Ocean captured at the same location where the photograph was originally taken that plays upon recognizing the image target. 


\section{Concluding Thoughts and Future Opportunities}

I have argued that augmented reality is an ideal immersive technology that can be harnessed to tell powerful stories using photographic collections material and a discovery-based learning approach. I have also looked at some recent and inspiring AR projects that demonstrate clearly the direction that this popular technology is taking and its potential. I have discussed the barriers to access and participate in this exciting use of augmented reality, and its use does present certain limitations and challenges; however, this may change as the technology evolves and becomes ubiquitous and art and cultural institutions move to make their cultural policies more democratic and their collections more accessible.

Through the creative project, I have demonstrated how AR combined with storytelling can be used to bring new life to photographic collections and archival material and extend situated exhibits in a meaningful way that aligns with the current trend of making museum content more engaging and interactive. The creative project aimed to test different applications of augmented reality for interpreting photographic material and related records in a collection and what unique opportunities AR provides.

The prototype designed for this project could be developed further into an application that could serve as a storytelling platform with AR features and could potentially be customized to suit the needs of any institution with a photographic collection. The prototype could also be fully developed as a unique storytelling piece on Clara Dennis and with culture and heritage grant funding, be realized as a situated exhibition within a museum in Nova Scotia or, alternately, adapted to be a location-based experience. 
Having the opportunity to view and interact with a historical print or archival object through AR seems like an ideal alternative, but the limitation is that you still can't quite touch the object. It is a bit of a tease. You see the object in front of you but can only touch the screen of whatever smart device you are using. Is an AR experience an adequate substitution for not being able to touch or handle a photograph? Perhaps not, but since there are significant reasons why these objects cannot be touched — and that will not change — it presents a more engaging and educational alternative to just browsing through the collection's database to see a digitized version or viewing a virtual exhibition on a museum's website. AR thus becomes a tool that archives and museums can leverage to increase engagement with their collections material; a tool that complements or enhances the viewing experience, rather than a substitution for touch.

Because photographs are both objects that have material and physical qualities, as well as images with aesthetic and information value, augmented reality seems like an ideal technology through which this complex nature and inherent duality can be understood. I am not suggesting that viewing and interacting with photographic material in augmented reality will or should replace the need to touch or interact with the original object, but it does have the potential to be used, in innovative ways, to enhance one's experience with photographic material. 


\section{Literature Cited}

A Hall Through New Eyes: Skin \& Bones, Smithsonian National Museum of Natural History, https://naturalhistory.si.edu/exhibits/bone-hall/

Anthropocene, https://theanthropocene.org/

Benjamin, Andrew. Walter Benjamin and Art. London: Continuum, 2005.

Cameron, Fiona, and Sarah Kenderdine. Theorizing Digital Cultural Heritage: A Critical Discourse. MIT Press, 2010.

Crawford, Dr. Brett Ashley, and Elizabeth Kane. The Augmented Museum: Essays on Opportunities and Uses of Augmented Reality in Museums, edited by Dr. Brett Ashley Crawford and Elizabeth Kane, 13-14. Pittsburgh, PA: Carnegie Mellon University: ETC Press, 2018.

"Clara Dennis LITT.D." Women-Biography. Halifax, 1952.

Photocopy from vertical file in reference section of Halifax Central Public Library

Data, http://wiki.creativecommons.org/Data

DeGeurin, Mack. "Internet Artists Invaded the MoMA With a Guerrilla Augmented Reality Exhibit." Motherboard, March 5, 2018.

https://motherboard.vice.com/en_us/article/8XD3mg/moma-augmented-reality-exhibitjackson-pollock-were-from-the-internet.

Dennis, Clara. Down in Nova Scotia. Toronto: Ryerson Press, 1934.

Dennis, Clara. More About Nova Scotia. Toronto: Ryerson Press, 1937.

Dennis, Clara. Cape Breton Over. Toronto: Ryerson Press, 1942.

Dennis, Clara. "Into the North of Cape Breton by Motor." Canadian Motorist, May 1929, 185.

"Dennis's 1929 Works Becomes Online Exhibit." Halifax Chronicle Herald, April 14, 2005. Photocopy of article from vertical file at Halifax Central Public Library

Ding, Mandy. "Augmented Reality in Museums." In The Augmented Museum: Essays on Opportunities and Uses of Augmented Reality in Museums, edited by Dr. Brett Ashley Crawford and Elizabeth Kane, 13-14. Pittsburgh, PA: Carnegie Mellon University: ETC Press, 2018.

Edwards, Elizabeth, and Janice Hart. Photographs Objects Histories: On the materiality of images. London: Routledge, 2010. 
$E H C$, http://www.heritagecities.com/stories/explore.

Fisher, Susan. "Forgotten Photographers." Photo Life, November 2006, 69-72.

Hylland, Ole Marius. "Even Better than the real thing? Digital Copies and Digital Museums in a Digital Cultural Policy." Culture Unbound Journal of Current Cultural Research 9, no. 1 (September 4, 2017): 62-84. doi:10.3384/cu.2000.1525.179162.

Katz, Miranda. "Augmented Reality is Transforming Museums," Wired, April 23, 2018, https://www.wired.com/story/augmented-reality-art-museums/

Kidd, Jenny. Museums in the New Mediascape: Transmedia, Participation, Ethics. Surrey, England: Ashgate Publishing Limited, 2014.

Livingstone, Sonia. "The Participation Paradigm in Audience Research." The Communication Review 16.1-2 (2013): 21-30. Accessed December 6, 2017.

Papagiannis, Helen. Augmented Human: How Technology Is Shaping the New Reality. Sebastopol, CA: O’Reilly Media, 2017.

Park, Jane. "National Libraries and a Museum open up their data using CC0," creative commons, March 12, 2012, https://creativecommons.org/2012/03/12/national-libraries-and-amuseum-open-up-their-data-using-cc0/

QR code, https://en.wikipedia.org/wiki/QR_code

ReBlink, Impossible Things, http://www.impossiblethings.co/project/reblink/

Rhodenizer, V.B. At the Sign of the Hand and Pen: Nova-Scotian Authors. Toronto: Canadiana House, 1968.

Shaw, Anny. "Edward Burtynsky unveils preview of Anthropocene Project at Photo London." Theartnewspaper.com, May 17, 2018. https://www.theartnewspaper.com/news/edward-burtynsky-unveils-preview-of-hisanthropocene-project-in-london.

Simon, Nina. The Participatory Museum. Santa Cruz, CA: Museum 2.0, 2010.

Something BIG has Come to Toronto: Augmented Reality in Ultimate Dinosaurs, Royal Ontario Museum, August 13, 2012, https://www.youtube.com/watch?v=2ZkZ3kW5CiM

"The First At-Large Member of Council." Journal of the Royal Nova Scotia Historical Society 8 (2005): 6-7. 
Trant, Jennifer. "When All You've Got is 'The Real Thing': museums and authenticity in the networked world." In Museums in a Digital Age, edited by Ross Parry, 306-313. London: Routledge, 2010.

Whitehead, Ruth Holmes. Niniskamijinaqik = Ancestral Images: The Mikmaq in Art and Photography. Halifax, N.S.: Nimbus Publishing, 2015.

"Writer Of Books On Nova Scotia, Dr. Clara Dennis, Dies In Halifax." Halifax Chronicle Herald, February 17, 1958. Photocopy of article from vertical file at Halifax Central Public Library 


\section{Endnotes}

i "ReBlink," Impossible Things, http://www.impossiblethings.co/project/reblink/; "Something BIG has Come to Toronto: Augmented Reality in Ultimate Dinosaurs,"Royal Ontario Museum, August 13, 2012, https://www.youtube.com/watch?v=2ZkZ3kW5CiM; "A Hall Through New Eyes: Skin \& Bones," Smithsonian National Museum of Natural History, https://naturalhistory.si.edu/exhibits/bone-hall/; EHC, http://www.heritagecities.com/stories/explore.

ii A Daguerreotype is a photograph made with a process that was introduced by Louis Jacques Mandé Daguerre in 1839 and used widely throughout the 1850s. The direct positive image has a copper plate support, covered with a layer of finely polished silver. Each Daguerreotype is a single, unique image. The image material is made up of tiny particles deposited on the polished silver surface. A Daguerreotype can appear as a positive or a negative, depending on how the plate is viewed. These unique photographs are often mounted in an ornate case with a hinged cover or housed in a passepartout style (frame).

iii Miranda Katz, "Augmented Reality is Transforming Museums," Wired, April 23, 2018, https://www.wired.com/story/augmented-reality-art-museums/; Mack DeGeurin, "Internet Artists Invaded the MoMA With a Guerrilla Augmented Reality Exhibit," Motherboard, March 5, 2018, https://motherboard.vice.com/en us/article/8XD3mg/moma-augmented-reality-exhibit-jacksonpollock-were-from-the-internet

iv Anthropocene, https://theanthropocene.org/

v The app is named Avara, https://www.avaramedia.com. Ed Burtynsky is a founder and member of the AVARA Media team. According to their website, "AVARA is developing a proprietary technology engine named Dune, with Blockchain and cryptocurrency at its foundation, that enables the creation of the most extraordinary Virtual Reality and Augmented Reality experiences with capabilities, interactions, user-generated content, and real-world connections that are non-existent today." The Anthropocene Project will be on exhibition at the AGO and the National Gallery of Canada beginning in September 2018 and will include both virtual and augmented reality experiences.

vi Jane Park, "National Libraries and a Museum open up their data using CC0," creative commons, March 12, 2012, https://creativecommons.org/2012/03/12/national-libraries-and-amuseum-open-up-their-data-using-cc0/; "Data," http://wiki.creativecommons.org/Data. Visit this site to learn more about creative commons licensing and data.

vii “QR code," https://en.wikipedia.org/wiki/QR_code. QR code (abbreviated from Quick Response Code) is a trademarked matrix barcode (two-dimensional barcode) first designed in 1994 for the automotive industry in Japan.

viii Ruth Holmes Whitehead has published several books on the Mi'kmaw throughout her career. In her most recent publication Niniskamijinaqik Ancestral Images: The Mi'kmaq in Art and Photography, Whitehead used several of Dennis's portraits, as well as some of her notes taken during her meetings with members of the Mi'kmaw communities.

ix Helen Creighton (September 5, 1899 - December 12, 1989) was a recognized Canadian folklorist. During her career which spanned several decades, Creighton collected around 4,000 
traditional stories, songs, and beliefs. She published several books and articles on Nova Scotian folklore and received several honorary degrees for her work. She was made a Member of the Order of Canada in 1976. Creighton has received criticism, however, by scholars like Ian McKay in his book Quest of the Folk: Antimodernism and Cultural Selection in Twentieth-Century Nova Scotia, for 'selective editing' and creating and perpetuating a myth of Nova Scotians as simpler and more idyllic people - a myth that commodified and demeaned the working-class people of Nova Scotia and shaped a very specific cultural narrative that suited tourism.

${ }^{x}$ Acadians began to settle Cap-Rouge in 1821 . What began as a small trail along the coast, eventually became part of the original Cabot Trail, connecting Chéticamp to Pleasant Bay in 1927. By 1932, the entire Cabot Trail was officially opened, followed by the formation of the Cape Breton Highlands National Park in 1936. In 1940, the old road to Cap-Rouge was closed in favour of establishing a less perilous route along Presqu'ile. A small Acadian community lived in the area for over a century before the land was expropriated to form the Cape Breton Highlands National Park. By 1941, most families had relocated to Chéticamp — also an area settled by Acadians in the $18^{\text {th }}$ century. 